\title{
Wave energy conversion by controlled floating and submerged cylindrical buoys
}

\author{
Umesh A. Korde ${ }^{1} \cdot$ R. Cengiz Ertekin ${ }^{2}$
}

Received: 18 August 2014 / Accepted: 15 March 2015 / Published online: 25 March 2015

(C) Springer International Publishing AG 2015

\begin{abstract}
This paper investigates the wave energy conversion performance of floating and submerged heaving vertical-cylinder buoys. Two types of reactive control strategies are evaluated for their effect on energy absorption in irregular waves described by uni-modal spectra. Approximate near-optimal reactive control based on up-wave surface elevation measurement and peak-frequency tuning are compared for performance improvements over constant-damping load. The paper describes time-domain calculations under unconstrained oscillation in long-crested irregular waves for two sets of buoy dimensions. Supporting analysis and frequency-domain calculations suggest that near-optimal control performs considerably better than peak-frequency tuning for the submerged buoys and somewhat better for the floating buoys. The relative contributions of the FroudeKrylov and diffraction force components, and wave radiation properties for the two configurations are found to be important in this context.
\end{abstract}

Keywords Wave energy · Vertical cylinders · Floating and submerged $\cdot$ Control strategies

Umesh A. Korde

Umesh.Korde@sdsmt.edu

R. Cengiz Ertekin

ertekin@hawaii.edu

1 Department of Mechanical Engineering, South Dakota School of Mines and Technology, Rapid City, SD 57701, USA

2 Department of Ocean and Resources Engineering, University of Hawaii at Manoa, Honolulu, HI 96822, USA

\section{List of symbols}

$\eta(x, t) \quad$ Wave surface elevation at position $x$ and time $t$

$\gamma$ Phase difference between the FroudeKrylov and the diffraction heave force components

$\omega \quad$ Wave/oscillation circular frequency

$\omega_{\mathrm{p}} \quad$ Spectral peak frequency

A Incident wave amplitude

$a(\omega) \quad$ Just the frequency-dependent added mass in heave; $\bar{a}(\omega)-\bar{a}(\infty)$

$a_{\mathrm{c}}(i \omega), b_{\mathrm{c}}(i \omega)$ Fourier transforms of the right-shifted, causalized, individual impulse response functions for $a(\omega)$ and $b(\omega)$

$b(\omega) \quad$ Radiation damping in heave

$c_{\mathrm{d}}$

$D$

$D_{\mathrm{r}}$

$F_{\mathrm{d}}$

$F_{\mathrm{f}}$

$F_{\mathrm{r}}$

$F_{\mathrm{fk}}$

$F_{\text {ro }}$

$g$

$h$

$h_{\mathrm{A}}, h_{\mathrm{R}}$

$H_{\mathrm{f}}$

$h_{\mathrm{f}}$

$h_{\mathrm{o}}$
Linearized viscous damping coefficient

Load damping in constant damping case $=R / 2$; Draft (submergence depth) for floating (submerged) buoy

Diffraction force component in heave Wave-applied exciting force in heave Force applied by the power take-off Froude-Krylov force component in heave Control force $F_{\mathrm{r}}$ required for maximum power absorption

Gravity acceleration

Water depth at buoy location

Impulse response functions used to model actual device response

Frequency response function in heave

Exciting force impulse response function in heave

Impulse response function representing the desired behavior 


\begin{tabular}{|c|c|}
\hline$h_{\mathrm{r}}$ & $\begin{array}{l}\text { Radiation impulse response function in } \\
\text { heave }\end{array}$ \\
\hline$H_{\mathrm{s}}$ & Significant wave height \\
\hline$H_{\mathrm{fd}}$ & $\begin{array}{l}\text { Fourier transform of the right-shifted } \\
\text { 'causalized' exciting force kernel }\end{array}$ \\
\hline$h_{11}, h_{12}, h_{\mathrm{a}}$ & $\begin{array}{l}\text { Impulse response functions defining the } \\
\text { resistive and reactive force applied in } \\
\text { near-optimal control }\end{array}$ \\
\hline$k$ & Wave number \\
\hline$k_{\mathrm{h}}$ & $\begin{array}{l}\text { Stiffness constant including mooring and } \\
\text { hydrostatic restoring constant }\end{array}$ \\
\hline$m$ & In-air mass of body \\
\hline$P_{\mathrm{f}}$ & $\begin{array}{l}\text { Power absorbed at each } k \text { with peak- } \\
\text { frequency tuning }\end{array}$ \\
\hline$P_{\mathrm{i}}$ & Incident wave power per unit crest width \\
\hline$P_{\mathrm{w}}$ & $\begin{array}{l}\text { Power absorbed at each } k \text { with near- } \\
\text { optimal control }\end{array}$ \\
\hline$P_{\mathrm{Da}}$ & $\begin{array}{l}\text { Average power absorbed under constant } \\
\text { damping in irregular waves }\end{array}$ \\
\hline$P_{\mathrm{fa}}$ & $\begin{array}{l}\text { Average power absorbed under peak- } \\
\text { frequency tuning in irregular waves }\end{array}$ \\
\hline$P_{\mathrm{wa}}$ & $\begin{array}{l}\text { Average power absorbed under approx- } \\
\text { imate near-optimal control in irregular } \\
\text { waves }\end{array}$ \\
\hline$R$ & Buoy radius \\
\hline$S(\omega)$ & Incident wave spectral density \\
\hline$T_{\mathrm{e}}$ & Energy period for the input spectrum \\
\hline$U_{\mathrm{opt}}$ & $\begin{array}{l}\text { Hydrodynamically optimum velocity in } \\
\text { frequency domain }\end{array}$ \\
\hline$v$ & Heave velocity \\
\hline$v_{\mathrm{m}}$ & $\begin{array}{l}\text { Actual velocity in heave under peak- } \\
\text { frequency tuning }\end{array}$ \\
\hline$v_{\mathrm{o}}$ & Desired optimum velocity in heave \\
\hline$v_{\text {act }}$ & $\begin{array}{l}\text { Actual velocity under near-optimum con- } \\
\text { trol in heave }\end{array}$ \\
\hline$v_{\mathrm{mx}}$ & Shallow water limit for group velocity \\
\hline $\bar{a}(\infty)$ & Infinite-frequency added mass in heave \\
\hline $\bar{a}(\omega)$ & $\begin{array}{l}\text { Added mass including the infinite- } \\
\text { frequency added mass }\end{array}$ \\
\hline
\end{tabular}

\section{Introduction}

The hydrodynamic behavior of floating axi-symmetric point absorbers capturing energy from heave oscillations has been studied since the early 1970s, see, e.g., McCormick (1981). Control is particularly desirable for such devices due to their narrow-band frequency response and short resonant periods. For such devices, Budal and Falnes (1980) introduced a latching type control approach using real-time application of clutching or braking forces. Since then, this approach has been investigated by many authors, see Hoskin et al. (1985), Falcao and Justino (1999), Perdigao and Sarmento (1989),
Korde (2001), and Babarit and Clement (2006), to name a few. A heaving buoy type device driving a hydraulic power take-off was considered more recently by Falcao (2008) for optimized conversion in the time domain. Frequencydomain 'complex-conjugate control' approaches comprising adjustable reactive loading for selective tuning to changing wave spectra have been studied since the mid-seventies, see, e.g., Salter (1978), Nebel (1992) and Korde (1991). Such an approach was tested recently on the Wavestar device in Denmark (e.g., Hansen and Kramer 2011).

Real-time control for optimum velocity operation in irregular waves presents fundamental difficulties, as outlined in Naito and Nakamura (1985), and later in Falnes (1995). Since wave radiation from body oscillation is causal, the radiation impulse response function is also causal. Therefore, the frequency-dependent added mass and radiation damping satisfy the Kramers-Kronig relations. For optimum velocity in irregular waves, the impulse response functions corresponding to these two quantities need to be synthesized and used independently, both of which are non-causal, one being symmetric and the other anti-symmetric. In part for this reason, control force synthesis at a given time instant requires knowledge or prediction of velocity into the future. Compromise solutions using velocity estimation based on time-series analysis of past velocities were reported several years ago by Korde (1999) and Korde et al. (2002). Recently, systematic studies were reported Fusco and Ringwood (2012) on the relation between the device geometry and the required 'prediction horizon'. More recent work followed an approach discussed in Naito and Nakamura (1985) and Falnes (1995) and used up-wave surface elevation measurements with right-shifted impulse response functions to generate approximate instantaneous control forces, see Korde (2014). Other approaches such as model predictive control and adaptive control have also been considered. Many of these were evaluated in a recent paper by Hals et al. (2011). Other more recently reported approaches include the simple and effective control strategy, Fusco and Ringwood (2013), and a robust controller suitable in the presence of model uncertainties and oscillation constraints, Fusco and Ringwood (2014). Force and displacement constraints were considered within a single framework in Bacelli and Ringwood (2012).

It is easy to see that control seeking tuning over an entire spectrum would enable better energy conversion in bi- or multi-modal spectra. However, for uni-modal and narrowband spectra, and especially for small heaving buoys, it can be argued that peak-frequency tuning (such as reported in Hansen and Kramer 2011) could produce comparable performance with less effort. The comparative assessment of different strategies in Hals et al. (2011) shows that, in longer periods, the peak-frequency tuning approach would perform comparably with other approaches seeking tuning over a 


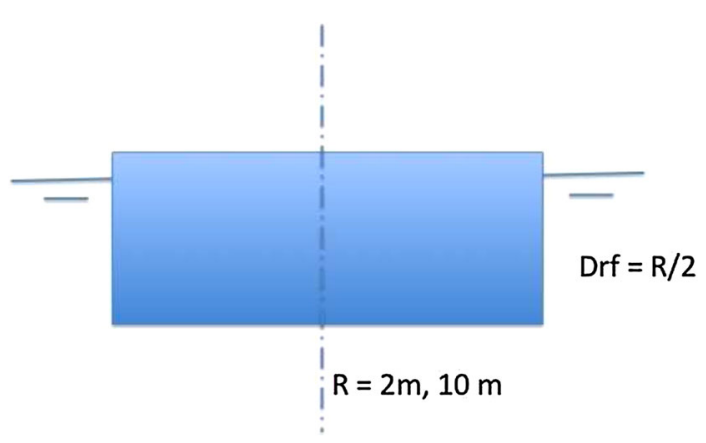

(a) Floating Buoy

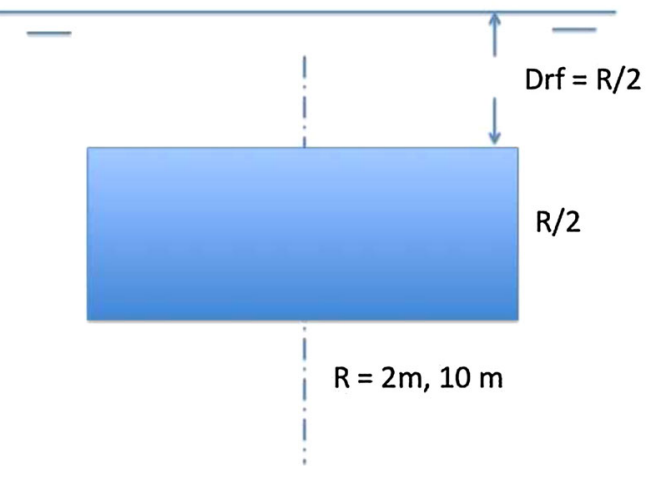

(b) Submerged Buoy

Fig. 1 A schematic view of the floating and submerged cylindrical buoy devices studied in this work. The floating and submerged configurations thus assume the same immersed geometry at static equilibrium, and the depth of submergence in the submerged case equals the draft in the floating case. For small deflections, the above-water portion of the floating buoy is assumed to be small

range of frequencies. This paper investigates this question further, for floating and submerged heaving devices. The findings are interpreted using an approximate analysis in the frequency domain. Effect of oscillation constraints is not difficult to study by extending the approach of this paper, but is not addressed in this paper. Only uni-modal spectra are considered in this work. As discussed in Falnes and Hals (2012), the floating and submerged configurations have considerably different wave radiation properties impacting their performance, especially in long waves.

Figure 1 shows a schematic diagram for the two situations studied in this paper. Section 2 summarizes the control strategies used. Note that the time-domain calculations are for unconstrained oscillation. Section 3 presents an approximate analysis to help to interpret the time-domain results, while Sects. 4 and 5 present and discuss principal results.

\section{Control formulation summary}

The control approaches used in this work are drawn from Korde (2014). The following outline is intended only to pro- vide a context for the subsequent discussion (see, e.g., Korde 2014 for details). The equation of motion for single-mode unconstrained heave velocity in an irregular wave train is

$$
\begin{aligned}
& {[m+\bar{a}(\infty)] \dot{v}+c_{\mathrm{d}} v+\int_{0}^{\infty} h_{\mathrm{r}}(\tau) v(t-\tau) \mathrm{d} \tau} \\
& \quad+k_{\mathrm{h}} \int_{-\infty}^{t} v(\tau) \mathrm{d} \tau=F_{\mathrm{f}}+F_{\mathrm{r}}
\end{aligned}
$$

where $F_{\mathrm{f}}$ represents the exciting force in heave, and $F_{\mathrm{r}}$ is the force applied by the power take-off. Here the total radiation force $F_{\mathrm{R}}$ on the body [to be placed on the right side of Eq. (1)] is expressed as:

$$
F_{\mathrm{R}}(t)=-\bar{a}(\infty) \dot{v}-\int_{0}^{\infty} h_{\mathrm{r}}(\tau) v(t-\tau) \mathrm{d} \tau
$$

The radiation impulse response function $h_{\mathrm{r}}(t)$ is causal in that only the past and present velocity affects the radiation force. Thus, $h_{\mathrm{r}}(t)=0, t<0$. This implies that its Fourier transform, $H(i \omega)$, is analytic in the upper half of the complex-frequency plane, see Wehausen (1992). Further, since $h_{\mathrm{r}}(t)$ is real-valued (velocity and radiation force being real-valued), $H_{\mathrm{r}}(-i \omega)=H_{\mathrm{r}}^{*}(i \omega)$. Further,

$\int_{-\infty}^{\infty} h_{\mathrm{r}}(t) \mathrm{e}^{-i \omega t} \mathrm{~d} t=H_{\mathrm{r}}(i \omega)=b(\omega)+i \omega[\bar{a}(\omega)-\bar{a}(\infty)]$,

where $b(\omega)$ is the frequency-dependent radiation damping, and for convenience $a(\omega)=\bar{a}(\omega)-\bar{a}(\infty)$ is used below to denote just the frequency-dependent added mass part. Thus, as

$$
\begin{aligned}
& \lim _{\omega \rightarrow \infty} \bar{a}(\omega)=\bar{a}(\infty), \\
& \lim _{\omega \rightarrow \infty} a(\omega) \rightarrow 0 .
\end{aligned}
$$

Note that there is a notational inconsistency in Korde (2014) where the symbol $\bar{a}(\infty)$ is used for the infinitefrequency added mass. As a consequence of causality of $h_{\mathrm{r}}(t)$ thus, $b(\omega)$ and $a(\omega)$ satisfy the Kramers-Kronig relations Jeffreys (1984), Falnes (2002), and others.

As a result of the above,

$b(\omega)=\int_{0}^{\infty} h_{\mathrm{r}}(t) \cos \omega t \mathrm{~d} t$,

$a(\omega)=-\frac{1}{\omega} \int_{0}^{\infty} h_{\mathrm{r}}(t) \sin \omega t \mathrm{~d} t$.

Note that the full Fourier transforms of $b(\omega)$ and $\omega a(\omega)$ must be even and odd functions of time and equal in magnitude $\left(=h_{\mathrm{r}}(t) / 2\right)$. Thus, 
$h_{\mathrm{b}}(t)=\frac{1}{2 \pi} \int_{-\infty}^{\infty} b(\omega) \mathrm{e}^{i \omega t} \mathrm{~d} \omega$,

$h_{\mathrm{a}}(t)=\frac{1}{2 \pi} \int_{-\infty}^{\infty} i \omega a(\omega) \mathrm{e}^{i \omega t} \mathrm{~d} \omega$

are both non-causal.

The exciting force $F_{\mathrm{f}}(t)$ may be written in terms of the wave surface elevation $\eta$ at the device centroid $x_{\mathrm{B}}$ as

$F_{\mathrm{f}}(t)=\int_{-\infty}^{\infty} H_{\mathrm{f}}(\tau) \eta\left(x_{\mathrm{B}} ; t-\tau\right) \mathrm{d} \tau$.

With respect to $\eta\left(x_{\mathrm{B}} ; t\right), H_{\mathrm{f}}$ is not causal, and $H_{\mathrm{f}}(t) \neq 0, t<$ 0 . For maximum energy absorption by an ideal single-mode device without viscous losses and without oscillation constraints, the reactive terms in Eq. (1) need to be externally forced out, and the rate of energy radiation from the device needs to be equaled by the rate of energy absorption by the power take-off. Thus, for maximum power absorption, the force $F_{\mathrm{r}}(t) \equiv F_{\text {ro }}(t)$ needs to be

$F_{\mathrm{ro}}(t)=[m+\bar{a}(\infty)] \dot{v}+k_{\mathrm{h}} \int_{-\infty}^{t} v(\tau) \mathrm{d} \tau+F_{\mathrm{c}}(t)$,

where the first two terms contain the frequency-independent inertia and stiffness effects only, and can be derived in real time using velocity and acceleration measurements at the current instant and no prediction is required. $F_{\mathrm{c}}(t)$ is the part that needs to provide the correct power absorption rate and cancel the remaining reactive effects. For the present device, $F_{\mathrm{c}}(t)$ is chosen to balance the total inherent damping effects (i.e., due to wave radiation and linearized viscous damping (see, e.g., Fusco and Ringwood 2014).

Though $H_{\mathrm{f}}$ and $h_{\mathrm{r}}$ (and consequently $h_{\mathrm{a}}$, and $h_{\mathrm{b}}$ ) are infinite time-interval impulse response functions in theory, in practice, they can be truncated at finite $t$ values $\left( \pm t_{\mathrm{c}}\right.$ for $h_{\mathrm{a}}$ and $h_{\mathrm{b}}$ and $\pm t_{\mathrm{f}}$ for $H_{\mathrm{f}}$ ) with small loss of accuracy. An approximation is proposed based on Naito and Nakamura (1985) [Equations (13)-(13") therein] and Falnes (1995) [equation (59) and discussion below equation (67)]. Thus,

$$
\begin{gathered}
F_{\mathrm{c}}(t) \approx-c_{\mathrm{d}} v(t)-\int_{-t_{c}}^{t_{c}} h_{\mathrm{b}}(\tau) v(t-\tau) \mathrm{d} \tau \\
+\int_{-t_{c}}^{t_{c}} h_{\mathrm{a}}(\tau) v(t-\tau) \mathrm{d} \tau .
\end{gathered}
$$

Note that when transposed to the left side of Eq. (1), the second and third terms combine to give the required approximate total anti-causal force. Further,

$F_{\mathrm{f}}(t) \approx \int_{-t_{f}}^{t_{f}} H_{\mathrm{f}}(\tau) \eta\left(x_{\mathrm{B}} ; t-\tau\right) \mathrm{d} \tau$
Following Korde (2014) [Equations (48)-(52) therein],

$F_{\mathrm{c}}(t)=F_{1}(t)+F_{\mathrm{a}}(t)$,

where

$$
\begin{aligned}
F_{1}(t)= & -\int_{0}^{2 t_{R}} h_{11}(\tau) \eta\left(x_{\mathrm{R}} ; t-\tau\right) \mathrm{d} \tau \\
& -\int_{0}^{2 t_{f}} h_{12}(\tau) \eta\left(x_{\mathrm{A}} ; t-\tau\right) \mathrm{d} \tau
\end{aligned}
$$

and

$F_{\mathrm{a}}(t)=\int_{0}^{2 t_{R}} h_{\mathrm{a}}(\tau) \eta\left(x_{\mathrm{R}} ; t-\tau\right) \mathrm{d} \tau$.

The impulse response functions $h_{11}, h_{12}$, and $h_{\mathrm{a}}$ here are defined as in Eqs. (15) and (16) below. It should be noted that the direct use of measurements $\eta\left(x_{\mathrm{R}} ; t\right)$ and $\eta\left(x_{\mathrm{A}} ; t\right)$ in these time-domain calculations relies on the assumption that most wave components in the approaching spectrum satisfy the long-wave approximation for the body.

Relative to the location of the device $x_{\mathrm{B}}$, the surface elevation is measured at

$x_{\mathrm{A}}=x_{\mathrm{B}}-v_{\mathrm{mx}} t_{\mathrm{f}} ;$ and $x_{\mathrm{R}}=x_{\mathrm{B}}-v_{\mathrm{mx}}\left(t_{\mathrm{c}}+t_{\mathrm{f}}\right) ; v_{\mathrm{mx}}=\sqrt{g h}$,

where $v_{\mathrm{mx}}$ is the group velocity in shallow water of the longest waves in the spectrum (at which propagation becomes non-dispersive), see Falnes (1995). In spectra dominated by long swells, all waves significant for energy conversion are here assumed to propagate at this speed. This approximation implies that for both the floating and the submerged configurations, the present control will perform better in spectra with longer energy periods. Note that this single group-velocity approximation is also used but not mentioned explicitly in Korde (2014).

The impulse response functions $h_{11}$ and $h_{12}$ are found as

$$
\begin{aligned}
& h_{11}(t)=\frac{1}{2 \pi} \int_{-\infty}^{\infty} \frac{b_{\mathrm{c}}(\omega) H_{\mathrm{fd}}(i \omega)}{2\left[c_{\mathrm{d}}+b(\omega)\right]} \mathrm{e}^{i \omega t} \mathrm{~d} \omega, \\
& h_{12}(t)=\frac{1}{2 \pi} \int_{-\infty}^{\infty} \frac{c_{\mathrm{d}} H_{\mathrm{fd}}(i \omega)}{2\left[c_{\mathrm{d}}+b(\omega)\right]} \mathrm{e}^{i \omega t} \mathrm{~d} \omega,
\end{aligned}
$$

whereas

$h_{\mathrm{a}}(t)=\frac{1}{2 \pi} \int_{-\infty}^{\infty} \frac{i \omega a_{\mathrm{c}}(i \omega) H_{\mathrm{fd}}(i \omega)}{2\left[c_{\mathrm{d}}+b(\omega)\right]} \mathrm{e}^{i \omega t} \mathrm{~d} \omega$.

The desired optimal velocity is found as

$v_{\mathrm{o}}(t)=\int_{0}^{2 t_{f}} h_{\mathrm{o}}(\tau) \eta\left(x_{\mathrm{A}} ; t-\tau\right) \mathrm{d} \tau$ 
where

$h_{\mathrm{o}}(t)=\frac{1}{2 \pi} \int_{-\infty}^{\infty} \frac{H_{\mathrm{fd}}(i \omega)}{2\left[b(\omega)+c_{\mathrm{d}}\right]} \mathrm{e}^{i \omega t} \mathrm{~d} \omega$.

The actual velocity under near-optimal control is

$$
\begin{aligned}
v_{\mathrm{act}}(t)= & \int_{0}^{2 t_{f}} h_{\mathrm{A}}(\tau) \eta\left(x_{\mathrm{A}} ; t-\tau\right) \mathrm{d} \tau \\
& +\int_{0}^{2 t_{f}} h_{\mathrm{R}}(\tau) \eta\left(x_{\mathrm{R}} ; t-\tau\right) \mathrm{d} \tau,
\end{aligned}
$$

with

$$
\begin{aligned}
& h_{\mathrm{A}}(t)=\frac{1}{2 \pi} \int_{-\infty}^{\infty} \frac{\left[c_{\mathrm{d}}+2 b(\omega)\right] H_{\mathrm{fd}}(i \omega)}{2\left[c_{\mathrm{d}}+b(\omega)\right]\left[i \omega a(\omega)+b(\omega)+c_{\mathrm{d}}\right]} \mathrm{e}^{i \omega t} \mathrm{~d} \omega, \\
& h_{\mathrm{R}}(t)=\frac{1}{2 \pi} \int_{-\infty}^{\infty} \frac{\left[i \omega a_{c}(i \omega)-b_{c}(i \omega)\right] H_{\mathrm{fd}}(i \omega)}{2\left[b(\omega)+c_{\mathrm{d}}\right]\left[i \omega a(\omega)+b(\omega)+c_{\mathrm{d}}\right]} \mathrm{e}^{i \omega t} \mathrm{~d} \omega .
\end{aligned}
$$

Control force for peak-frequency tuning is

$F_{\mathrm{c}}(t)=-c_{\mathrm{d}} v(t)-b\left(\omega_{\mathrm{p}}\right) v(t)+a\left(\omega_{\mathrm{p}}\right) \dot{v}(t)$.

The velocity $v=v_{\mathrm{m}}$ in peak-frequency tuning via Eq. (21) is found as

$v_{\mathrm{m}}(t)=\int_{0}^{2 t_{f}} h_{\mathrm{fc}}(\tau) \eta\left(x_{\mathrm{A}} ; t-\tau\right) \mathrm{d} \tau$,

where

$$
\begin{aligned}
& h_{\mathrm{fc}}(t) \\
& =\frac{1}{2 \pi} \int_{-\infty}^{\infty} \frac{H_{\mathrm{fd}}(i \omega)}{i \omega\left[a(\omega)-a\left(\omega_{\mathrm{p}}\right)\right]+\left[b(\omega)+b\left(\omega_{\mathrm{p}}\right)+2 c_{\mathrm{d}}\right]} \mathrm{e}^{i \omega t} \mathrm{~d} \omega .
\end{aligned}
$$

Equations (22) and (23) are used here for convenience in calculations, though in experiments, $b\left(\omega_{\mathrm{p}}\right)$ and $a\left(\omega_{\mathrm{p}}\right)$ may be continually adjusted using non-real time wave spectrum information. Although the primary goal here was to compare the approximate near-optimal control and peak frequency tuning strategies, calculations were also carried out for a case with no control and constant damping. Here,

$F_{\mathrm{r}}(t)=-D v(t)$

where $D$ denotes a non-optimized constant load damping value, held constant through all spectra.

For an irregular wave input (generated using a 2-parameter Pierson-Moskowitz-type spectrum), the average absorbed power for the three cases was found as summarized below. For the approximate near-optimal control,

$P_{\mathrm{wa}}=\frac{1}{T} \int_{0}^{T} F_{1}(t) v_{\mathrm{act}}(t) \mathrm{d} t$, for peak-frequency tuning,

$P_{\mathrm{fa}}=\frac{1}{T} \int_{0}^{T}\left[b\left(\omega_{\mathrm{p}}\right)+c_{\mathrm{d}}\right] v_{m}^{2}(t) \mathrm{d} t$,

while for constant damping,

$P_{\mathrm{Da}}=\frac{1}{2} \int_{0}^{T} D v^{2}(t) \mathrm{d} t$

All impulse response functions above, including $h_{11}$, $h_{12}, h_{\mathrm{a}}, h_{\mathrm{o}}, h_{\mathrm{A}}$, and $h_{\mathrm{R}}$ are evaluated using a numerical implementation of the inverse Fourier transforms in Eqs. (15), (16), (18) and (20), respectively.

\section{Floating and submerged buoys}

Assuming linearity, the heave exciting force can be expressed as:

$F_{\mathrm{f}}=F_{\mathrm{fk}}+F_{\mathrm{d}}$

where $F_{\mathrm{f}}, F_{\mathrm{fk}}$ and $F_{\mathrm{d}}$ are all complex. The Froude-Krylov component $F_{\mathrm{fk}}$ represents the contribution of the incidentwave velocity potential, and the diffraction component $F_{\mathrm{d}}$ represents the contribution of just the diffraction effects. Further,

$\left|F_{\mathrm{f}}\right|^{2}=\left|F_{\mathrm{fk}}\right|^{2}+\left|F_{\mathrm{d}}\right|^{2}+2\left|F_{\mathrm{fk}}\right|\left|F_{\mathrm{d}}\right| \cos \gamma$,

where $\gamma$ is the phase difference between the two components $F_{\mathrm{fk}}$ and $F_{\mathrm{d}}$. It may be noted that only the magnitudes of the individual terms in Eq. (29) are compared here to gain an understanding of their relative contributions to the total exciting force and radiation damping. No direct calculation requiring $\gamma$ is performed in this paper.

Figure 2 shows the heave exciting force components for the floating and the submerged buoys. As $k R \rightarrow 0, F_{\mathrm{d}} \rightarrow 0$ for both cases. However, over the wider $k R \ll 1$ region, the principal difference between the two is due to the relative contribution of the Froude-Krylov component $F_{\mathrm{fk}}$. While $F_{f k}$ is the dominant term for the floating case for $k R \ll 1$, for the submerged case, its contribution over $k R \ll 1$ is comparable to that of $F_{\mathrm{d}}$ or smaller. In fact, for a floating cylinder of radius $R=10 \mathrm{~m}$, and draft $D_{\mathrm{r}}=R / 2=5 \mathrm{~m}$, the total exciting force variation is dominated by the Froude-Krylov force even at the spectral peak frequency for a swell-dominated two-parameter spectrum, here with significant wave height $H_{\mathrm{s}}=1 \mathrm{~m}$ and energy period $T_{\mathrm{e}}=13 \mathrm{~s}$ (see also Budal and Falnes 1980).

Note that it is only the bottom surface area of the buoy that contributes to the heave exciting force in the case of the 


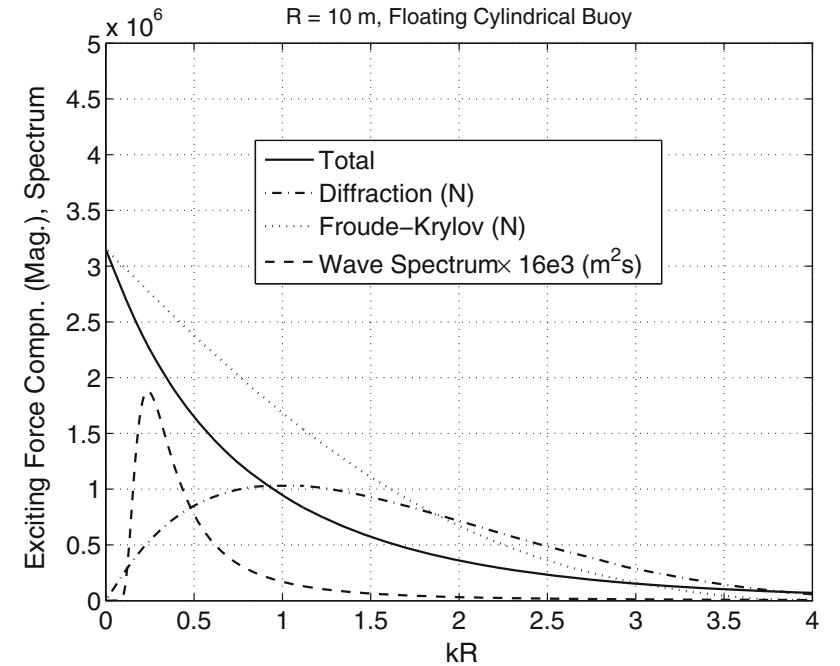

(a) Floating Buoy

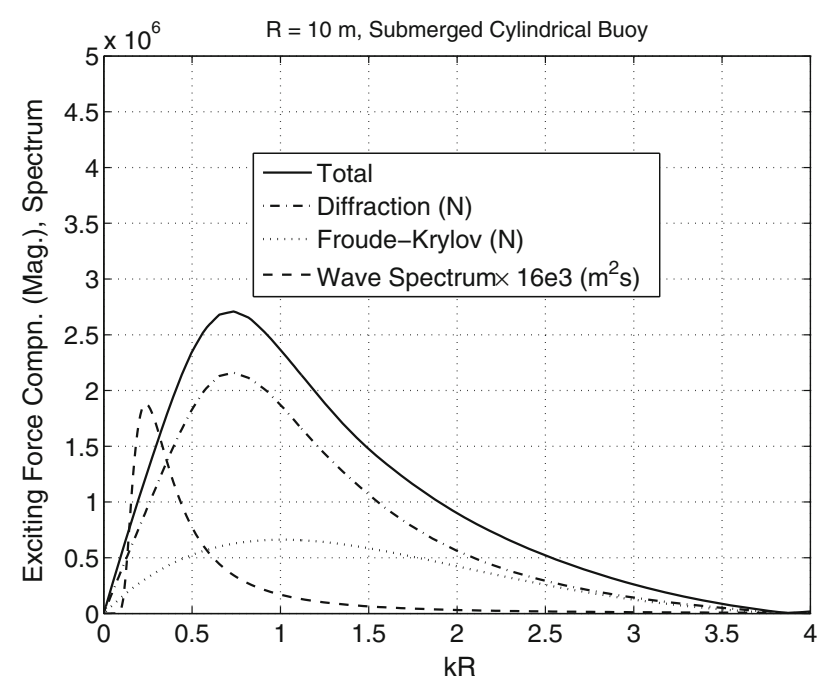

(b) Submerged Buoy

Fig. 2 Exciting force components in heave; Froude-Krylov component, diffraction component, and total force. Also shown is the incident wave spectrum for $H_{\mathrm{s}}=1 \mathrm{~m}$ and $T_{\mathrm{e}}=11 \mathrm{~s}$. 'Wave spectrum' in the legend refers to spectral density. Vertical scale represents exciting force components in $\mathrm{N}$ and spectral density in $\mathrm{m}^{2} \mathrm{~s} \times 16 \times 10^{3}$. At small $k R$ values, the Froude-Krylov component dominates for the floating case

floating cylinder. On the other hand, for a submerged cylinder $R=10 \mathrm{~m}$, height $D=5 \mathrm{~m}$, and depth of submergence $D_{\mathrm{r}}=D$, both the top and the bottom surfaces contribute to the heave exciting force. For a submerged cylinder height $D / R<\mathcal{O}(1)$, this implies that the Froude-Krylov component is small, and that the diffraction component, though small, may even be the dominant term. Correspondingly, given the reciprocity between exciting force on body surface and far-field radiation, the radiation properties in heave for the two configurations are also different.

It is well known that, for single-mode devices, optimum conversion without oscillation constraints and without vis- cous losses requires, in addition to resonance, that the energy conversion rate as given by the load damping match the energy radiation rate as determined by the radiation damping, Evans (1981). Radiation damping is a crucial parameter for this reason. In addition, larger radiation damping implies that optimum conversion requires smaller velocity. Since large velocities are physically challenging, larger radiation damping values are desirable, especially at lower frequencies where greater energy is available. For these reasons, it is of interest to compare the radiation damping values at the spectral peak frequencies for the floating vs. submerged cylindrical buoys.

At optimum conversion, the absorbed power at each wave number is

$P_{\mathrm{w}}(k)=\frac{1}{2} b(k)\left|U_{\mathrm{opt}}(k)\right|^{2}$,

where $U_{\mathrm{opt}}$ denotes the hydrodynamically optimum velocity in frequency domain. An application of Haskind-Hanaoka relations suggests (Wehausen 1971, see also, e.g., Yeung et al. 2012)

$b(k)=\frac{k}{8 P_{\mathrm{i}}}\left|F_{\mathrm{f}}(k)\right|^{2}$,

where $P_{\mathrm{i}}$ is the incident wave power per unit crest width. Figure 3 shows the radiation damping for the cylinder with $R=10 \mathrm{~m}$ with an example incident 2-parameter PiersonMoskowitz-type wave spectrum with $H_{\mathrm{s}}=1.0 \mathrm{~m}$, and $T_{\mathrm{e}}=13 \mathrm{~s}$ superimposed. In light of the comments following Eq. (29), it may be expected that the radiation damping in larger waves is dominated by the Froude-Krylov force for the floating buoys, whereas for the submerged buoys, it is dominated by the diffraction force. As the Froude-Krylov component is large near $k R \rightarrow 0$ for floating buoys, radiation damping peaks at a lower $k R$ for the floating buoy in Fig. 3. On the other hand, for the submerged buoys, the radiation damping peaks at a greater $k R$, closer to where the diffraction force peaks. It may also be recalled that, as $k R\left(k D_{\mathrm{r}}\right) \rightarrow 0$, the two faces of the submerged buoy counteract each other's wave radiation, Falnes and Hals (2012). It should be mentioned that the sharp corner observed near $k R \rightarrow 3$ in Fig. 3 is due to an approximation used to treat an 'irregular frequency' arising in the numerical calculations for the floating buoy HYDRAN (2012).

For deep water conditions, with $k=\omega^{2} / g$, of particular note are the $b(k)$ values near $\omega(k) \rightarrow \omega_{1}$, where $\omega_{1}$ is the lower frequency at which the spectral density $S(\omega) \rightarrow 0$. With $\omega_{\mathrm{p}}$ denoting the spectral peak frequency, an inspection of swell-dominated spectra with relatively long tails shows that $\left|\omega_{\mathrm{p}}-\omega_{\mathrm{l}}\right| \ll\left|\omega_{\mathrm{h}}-\omega_{\mathrm{p}}\right|$, where $\omega_{\mathrm{h}}$ denotes the higher frequency at which $S(\omega) \rightarrow 0$. The value of $b(k)$ at $k_{\mathrm{p}}$, the peak wave number, could be expressed using a Taylor series expansion about $\omega_{1}$ : 


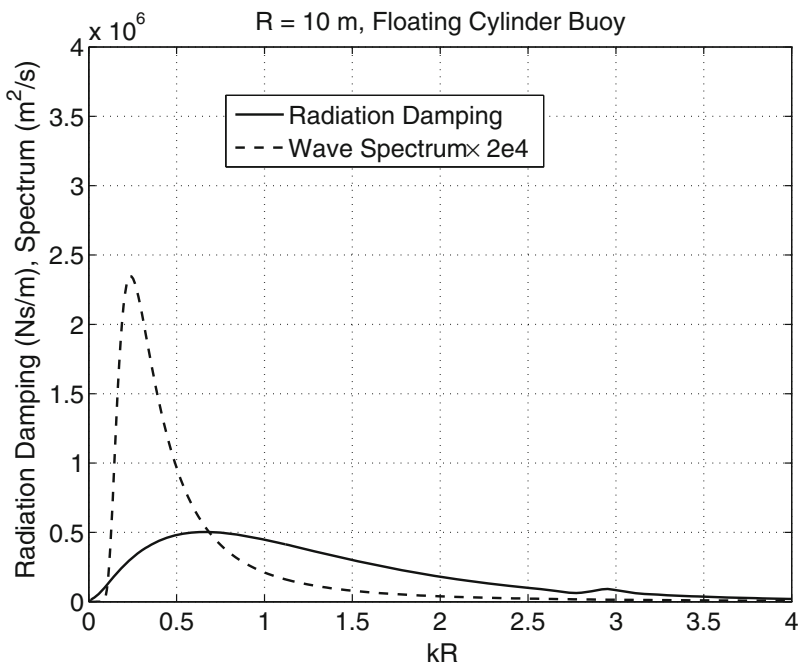

(a) Floating Buoy

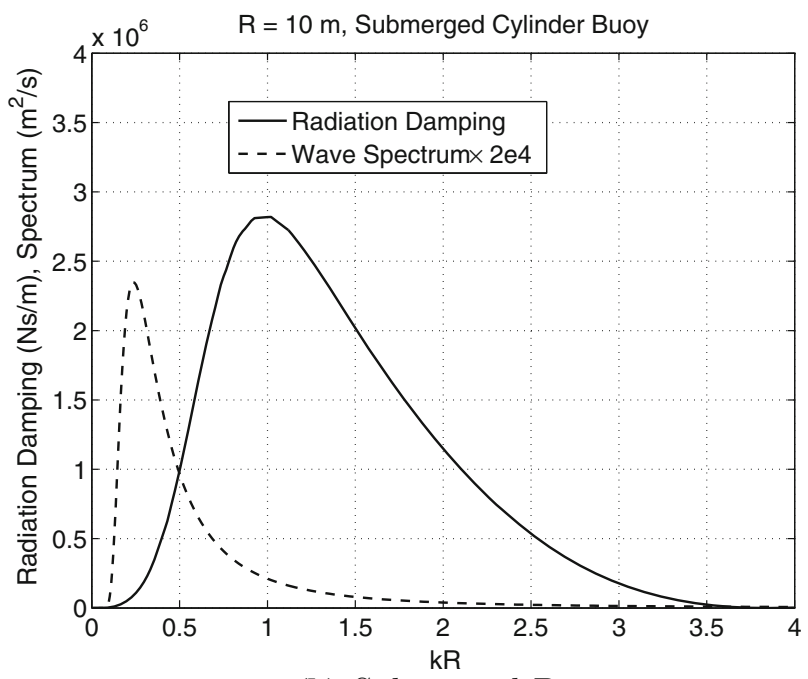

(b) Submerged Buoy

Fig. 3 Radiation damping in heave and the incident wave spectral density for $T_{\mathrm{e}}=13 \mathrm{~s}$. 'Spectrum' refers to spectral density in $\mathrm{m}^{2} \mathrm{~s}$. Vertical scale here represents damping values in $\mathrm{Ns} / \mathrm{m}$ and spectral density in $\mathrm{m}^{2} \mathrm{~s} \times$ a scaling constant. Owing to the large presence of the FroudeKrylov component near $k R \rightarrow 0$ for the floating buoy, the radiation damping peaks at lower $k R$ compared with the submerged case. The 'kink' near $k R \rightarrow 3$ for the floating buoy is due to an approximation used to treat an 'irregular frequency' in the numerical code used HYDRAN (2012)

$$
\begin{aligned}
b\left(k_{\mathrm{p}}\right)= & b\left(k_{1}\right)+\left[\frac{\mathrm{d} b}{\mathrm{~d} k}\right]_{k=k_{1}}\left(k_{\mathrm{p}}-k_{1}\right) \\
& +\frac{1}{2 !}\left[\frac{\mathrm{d}^{2} b}{\mathrm{~d} k^{2}}\right]_{k=k_{1}}\left(k_{\mathrm{p}}-k_{1}\right)^{2}+\cdots .
\end{aligned}
$$

Since $\left(k_{\mathrm{p}}-k_{1}\right)<\mathcal{O}\left(10^{-1}\right)$ for swell-dominated narrow-band spectra,

$b\left(k_{\mathrm{p}}\right) \approx b\left(k_{1}\right)+\left[\frac{\mathrm{d} b}{\mathrm{~d} k}\right]_{k_{1}}\left(k_{\mathrm{p}}-k_{1}\right)$.

\subsection{Floating buoys}

For the floating buoys in the region $k R \ll 1$,

$F_{\mathrm{f}} \approx F_{\mathrm{fk}}$,

where $F_{\mathrm{fk}}$ can be estimated using

$F_{\mathrm{fk}}=\rho g A \pi R^{2} \mathrm{e}^{-k D_{\mathrm{r}}}$.

For $k D_{\mathrm{r}} \sim \mathcal{O}\left(10^{-1}\right)$ (e.g., for a peak period $T_{p}=12 \mathrm{~s}$, with $\omega_{\mathrm{p}}=0.523 \mathrm{rad} / \mathrm{s}$ leading to $k=0.028 \Rightarrow k D_{\mathrm{r}}=0.056$ for $R=2 \mathrm{~m}, D_{\mathrm{r}}=R / 2$ and $k D_{\mathrm{r}}=0.14$ for $R=10 \mathrm{~m}, D_{\mathrm{r}}=$ $R / 2$ for the same peak period). Using a series expansion for the exponential,

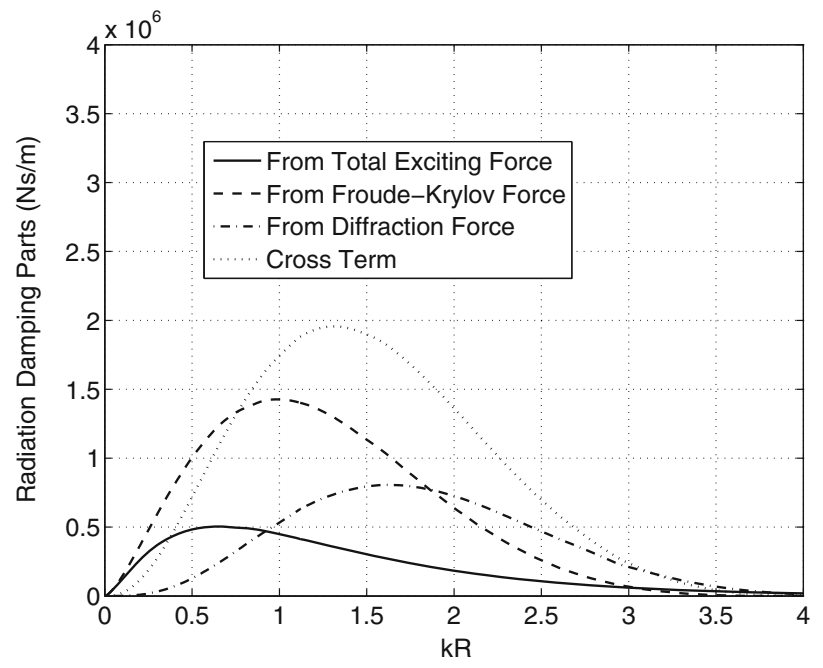

(a) Floating Buoy

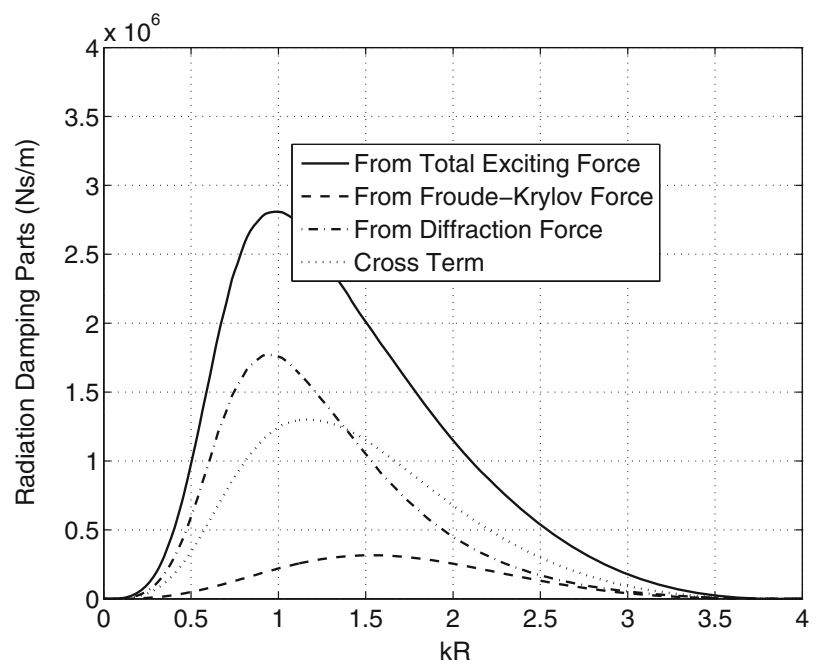

(b) Submerged Buoy

Fig. 4 Contribution of the different force components to radiation damping. 'Cross-term' refers to just the magnitude $2\left|F_{\mathrm{d}}\right|\left|F_{\mathrm{fk}}\right|$. At small $k R$ values, for the floating buoy the contribution of the Froude-Krylov force dominates, while it is the diffraction force contribution that dominates at small $k R$ for the submerged buoy 
$F_{\mathrm{fk}}=\rho g A \pi R^{2}\left(1-k D_{\mathrm{r}}+\frac{\left(k D_{\mathrm{r}}\right)^{2}}{2 !}-\frac{\left(k D_{\mathrm{r}}\right)^{3}}{3 !}+\cdots\right)$,

and keeping terms up to $\mathcal{O}\left(10^{-2}\right)$,

$F_{\mathrm{fk}} \approx \rho g A \pi R^{2}\left(1-k D_{\mathrm{r}}+\frac{\left(k D_{\mathrm{r}}\right)^{2}}{2 !}\right)$,

the leading order term is seen to be $\rho g A \pi R^{2}$.

When $F_{\mathrm{f}} \approx F_{\mathrm{fk}}$ at low frequencies (wave numbers), a low-frequency approximation for $b(k)$ can be written as:

$b(k) \approx \frac{k}{8 P_{\mathrm{i}}}\left|F_{\mathrm{fk}}\right|^{2}$.

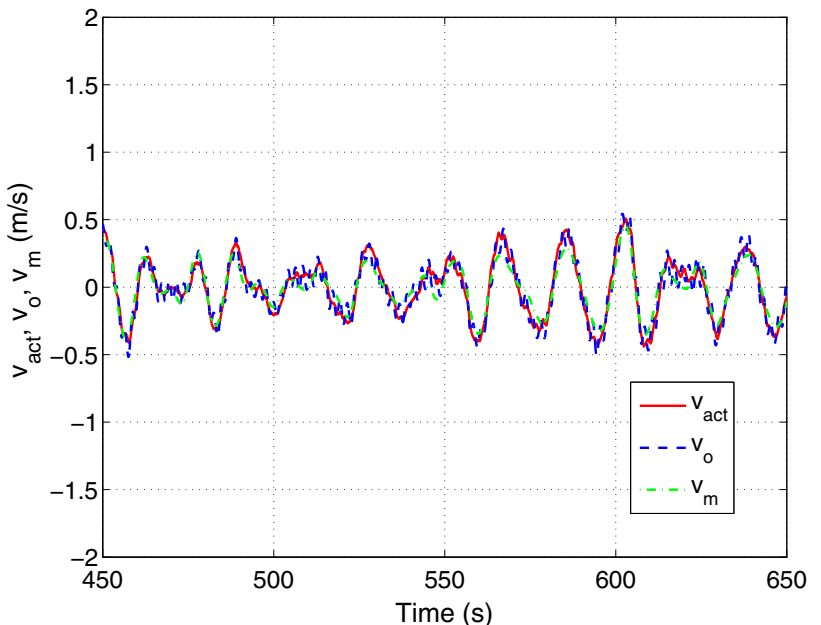

(a) Floating Buoy

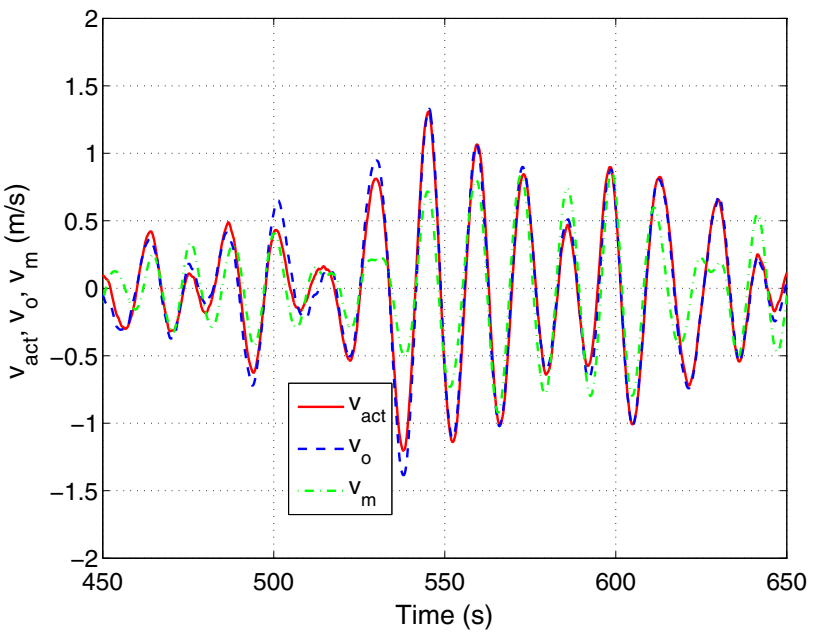

(b) Submerged Buoy

Fig. 5 The heave velocity of the $R=10 \mathrm{~m}$ buoy in a spectrum with $H_{\mathrm{s}}=1 \mathrm{~m}, T_{\mathrm{e}}=13 \mathrm{~s}$. Note that the velocity under peak frequency tuning is closer to the velocity under approximate near-optimal control for the floating buoy than for the submerged buoy. Oscillations are left unconstrained
Since $P_{\mathrm{i}}=\rho g^{2} A^{2} /(4 \omega)=\rho g^{3 / 2} A^{2} k^{-1 / 2} / 4$, using Eq. (35), for small $k$

$b(k)=\frac{1}{2} \rho g^{1 / 2} k^{3 / 2} \pi^{2} R^{4} \mathrm{e}^{-2 k D_{\mathrm{r}}}$.

For the floating cylinder, Eqs. (32), (33), and (39) lead to

$\frac{\mathrm{d} b}{\mathrm{~d} k}=\frac{1}{2} k^{1 / 2} \rho g^{1 / 2} \pi^{2} R^{4}\left(\frac{3}{2}-2 k D_{\mathrm{r}}\right) \mathrm{e}^{-2 k D_{\mathrm{r}}}$

With a series approximation,

$$
\begin{aligned}
b\left(k_{\mathrm{p}}\right) \approx & \frac{3}{4} k_{l}^{3 / 2} \rho g^{1 / 2} \pi^{2} R^{4}\left[1-2 k_{1} D_{\mathrm{r}}+2\left(k_{1} D_{\mathrm{r}}\right)^{2}\right] \\
& \times\left(1+\frac{1}{2} k_{1} D_{\mathrm{r}}\right)
\end{aligned}
$$

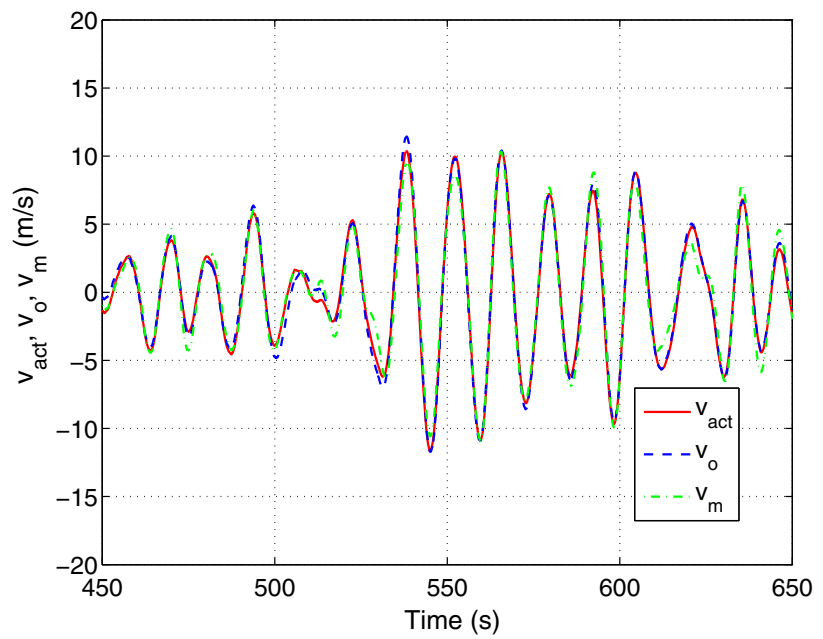

(a) Floating Buoy

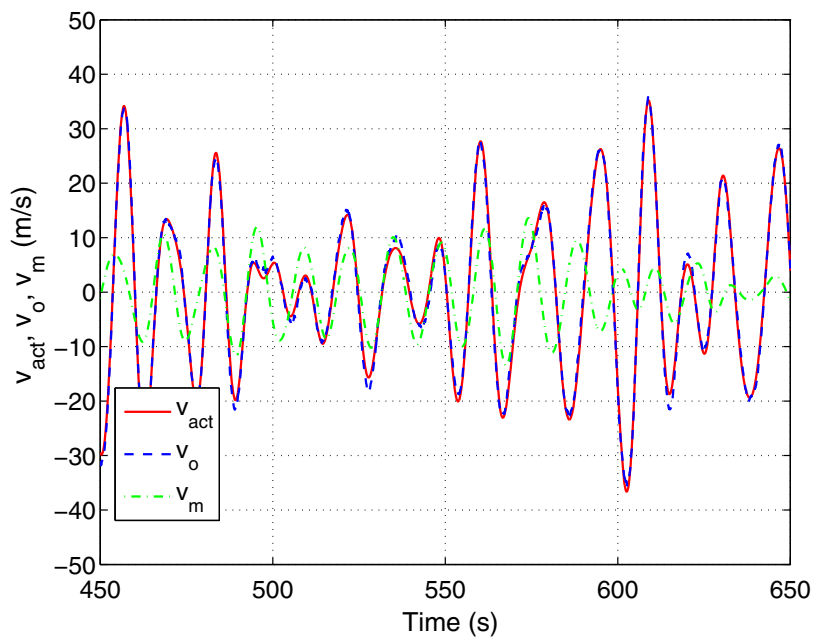

(b) Submerged Buoy

Fig. 6 The heave velocity of the $R=2 \mathrm{~m}$ buoy in a spectrum with $H_{\mathrm{s}}=1 \mathrm{~m}, T_{\mathrm{e}}=13 \mathrm{~s}$. Note that the difference between the velocities with peak frequency tuning and approximate near-optimal control is greater for the submerged buoy. No constraints are applied 
and

$$
\begin{aligned}
\left(\frac{\mathrm{d} b}{\mathrm{~d} k}\right)_{k=k_{\mathrm{p}}} \approx & \frac{1}{2} k_{l}^{1 / 2} \rho g^{1 / 2} \pi^{2} R^{4}\left[1-2 k_{1} D_{\mathrm{r}}+2\left(k_{1} D_{\mathrm{r}}\right)^{2}\right] \\
& \times\left(\frac{3}{2}-k_{1} D_{\mathrm{r}}\right) .
\end{aligned}
$$

\subsection{Submerged buoys}

For the submerged buoys in heave, $F_{\mathrm{d}}$ and $F_{\mathrm{fk}}$ may be comparable over $k R \ll 1$. Here, the depth of submergence $D_{\mathrm{s}}$ is the same as its height $\equiv D_{\mathrm{r}}$. Further, with $D_{\mathrm{r}}=R / 2, k D_{\mathrm{r}} \ll 1$. It is known that $F_{\mathrm{d}} \sim k R\left(k D_{\mathrm{r}}\right)$ over $k R\left(k D_{\mathrm{r}}\right) \ll 1$. The following steps demonstrate why the Froude-Krylov com-

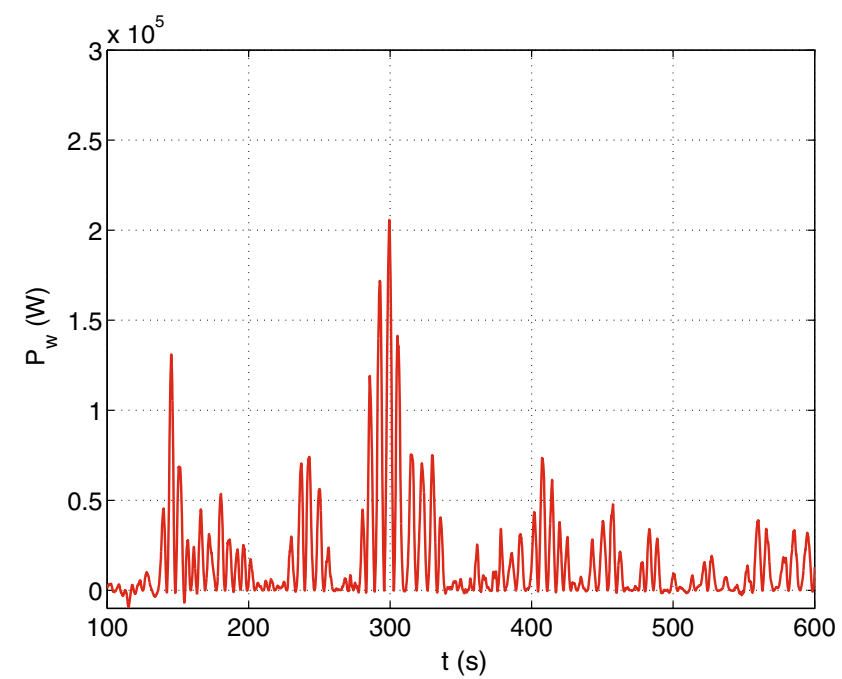

(a) Floating Buoy: Near-Optimum Control; $R=10 \mathrm{~m}$ ponent here also varies as $k R\left(k D_{\mathrm{r}}\right)$ and is not as large as in the floating case.

$F_{\mathrm{fk}}=\rho g A \pi R^{2}\left(-\mathrm{e}^{-k D_{\mathrm{r}}}+\mathrm{e}^{-2 k D_{\mathrm{r}}}\right)$.

Using series expansions for both exponentials and keeping terms up to second order,

$F_{\mathrm{fk}} \approx \rho g A \pi R^{2}\left(-k D_{\mathrm{r}}+\frac{3}{2}\left(k D_{\mathrm{r}}\right)^{2}\right)$.

The leading-order term for the submerged vertical cylinder is thus $-\rho g A \pi R^{2}\left(k D_{\mathrm{r}}\right)$, which is $\sim \mathcal{O}\left(10^{-1}\right)$ smaller than that for the floating cylinder.

As no single force component dominates for the submerged buoy, and both diffraction and Froude-Krylov com-

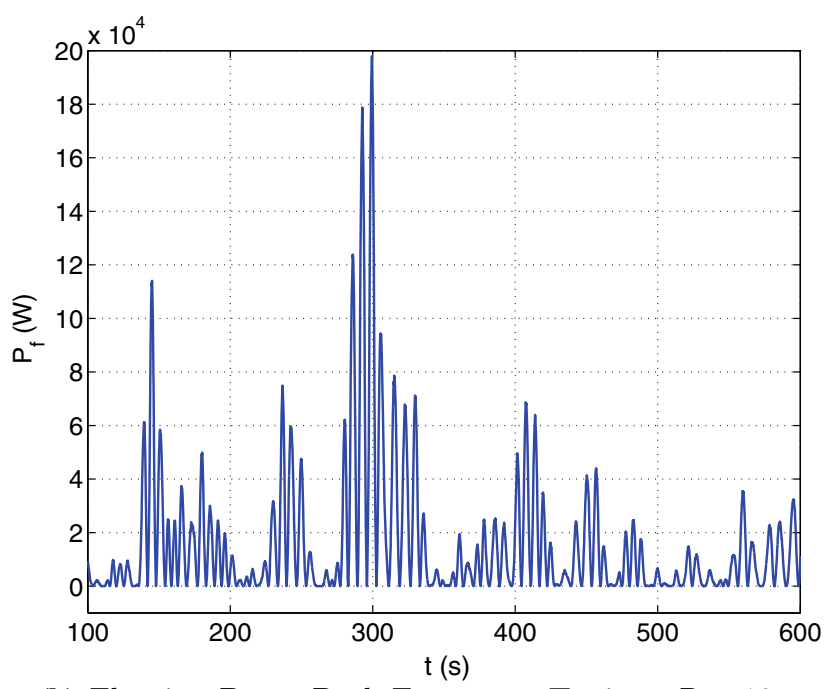

(b) Floating Buoy: Peak-Frequency Tuning; $R=10 \mathrm{~m}$

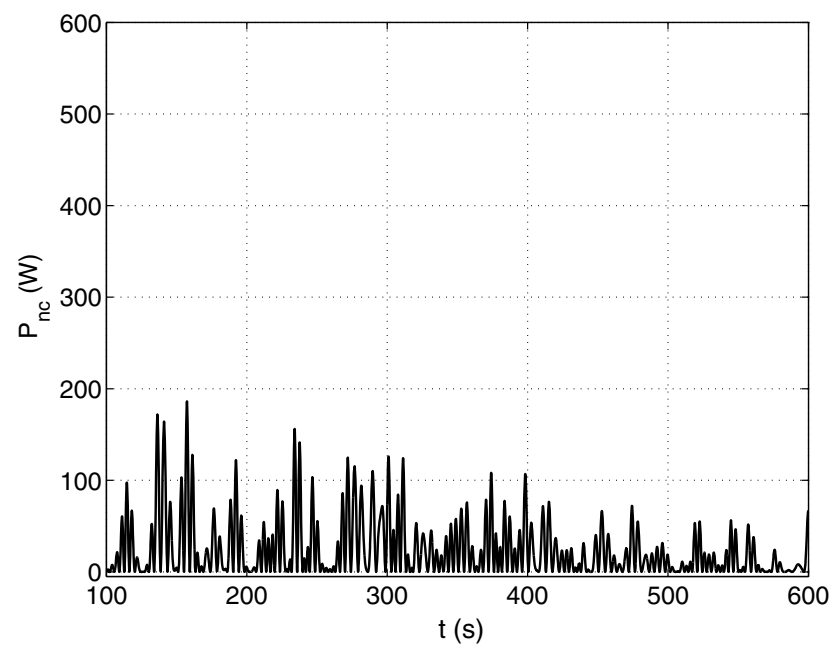

(c) Floating Buoy: Constant Damping; $R=10 \mathrm{~m}$

Fig. 7 The instantaneous power absorption by the $R=10 \mathrm{~m}$ floating buoy in a spectrum with $H_{\mathrm{s}}=1 \mathrm{~m}, T_{\mathrm{e}}=13 \mathrm{~s}$. Note the vertical axis scale difference on the third plot. Power absorption is considerably more efficient for the cases with approximate near-optimal control and peak frequency tuning than for the case with constant damping 
ponents are $\sim \mathcal{O}\left(k D_{\mathrm{r}}\right)$ smaller than the force on the floating buoy, $b(k)$ and $(\mathrm{d} b / \mathrm{d} k)_{k=k_{1}}$ for the submerged buoy are at least $\sim \mathcal{O}\left(k D_{\mathrm{r}}\right)$ smaller than the corresponding quantities for the floating buoy. Then, $b\left(k_{\mathrm{p}}\right)$ at the peak frequency for the submerged buoy is also at least $\mathcal{O}\left(k D_{\mathrm{r}}\right)$ smaller than for the floating buoy, for $k_{\mathrm{p}} D_{\mathrm{r}} \ll 1$.

\subsection{General}

It is interesting to note from Fig. 3 that although the radiation damping for the floating buoy peaks at a lower $k R$ value, the actual peak magnitude for floating buoy is less than that for the submerged buoy (see also Fig. 2, showing that the total exciting force for the submerged buoy is about 2.5 times that for the floating buoy as $k R \rightarrow 1$ ). The floating buoy radiates as a monopole in heave with only one face contributing.

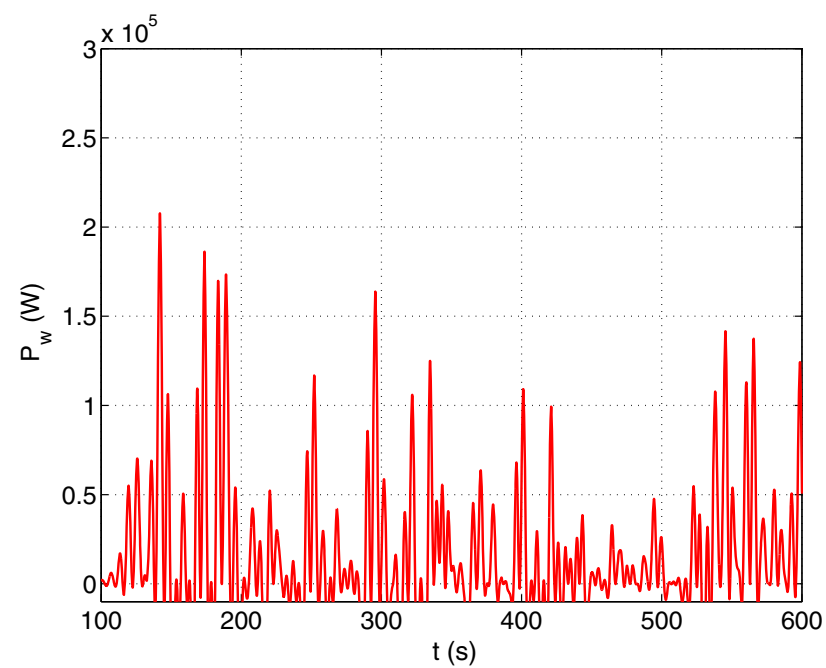

(a) Submerged Buoy: Near-Optimum Control; $R=10 \mathrm{~m}$
As $k R$ decreases below $k R<0.2$, however, the monopole behavior of the heaving floating buoy leads to more wave radiation than the submerged buoy in heave. As discussed in Falnes and Hals (2012), the submerged buoy also radiates as a monopole in heave with a radially symmetric wave field, but the top and bottom faces counteract each other's action.

Figure 4 compares the contributions of the various force components to the radiation damping for both floating and submerged buoys. The entry 'cross-term' in the legend refers to just the magnitude of product term in Eq. (29). As pointed out analytically above for the floating buoy, the contribution of the Froude-Krylov force component dominates at $k D_{\mathrm{r}} \ll$ $1(k R \ll 0.5)$, while all three are comparable for that range for the submerged buoy (see for instance the variations over $k R \leq 0.25$ in Figs. 3 and 4 ).

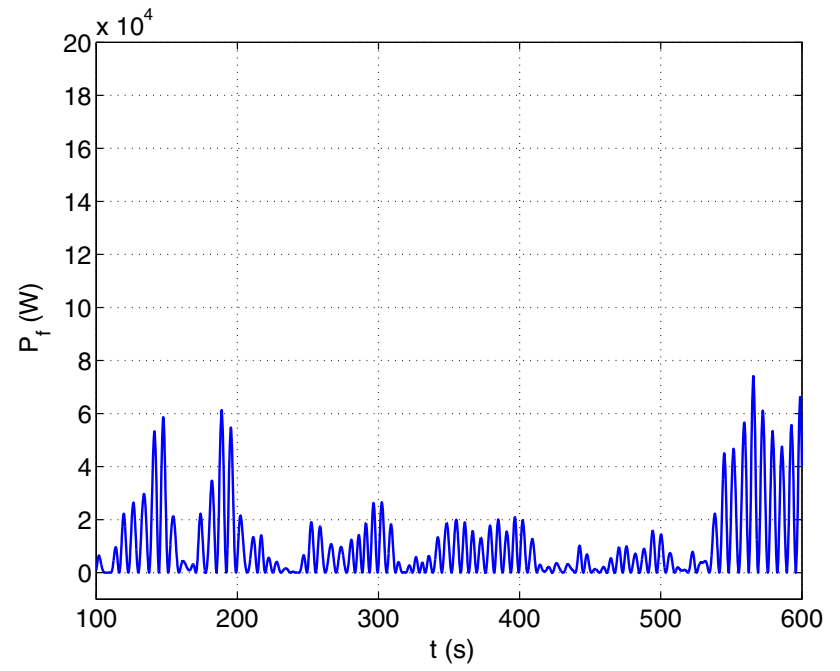

(b) Submerged Buoy: Peak-Frequency Tuning; $R=10 \mathrm{~m}$

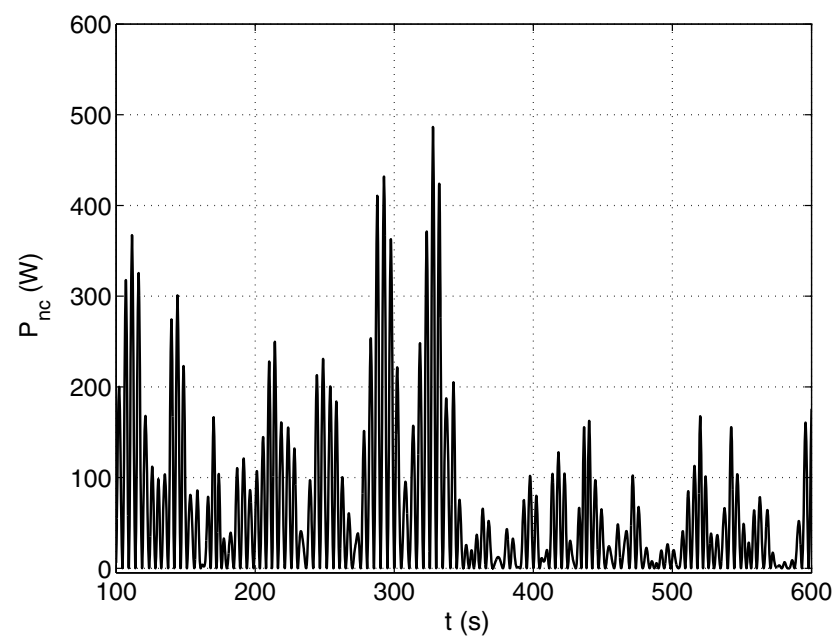

(c) Submerged Buoy: Constant Damping; $R=10 \mathrm{~m}$

Fig. 8 The instantaneous power absorption by the $R=10 \mathrm{~m}$ submerged buoy in a spectrum with $H_{\mathrm{s}}=1 \mathrm{~m}, T_{\mathrm{e}}=13 \mathrm{~s}$. Note the vertical axis scale difference on the third plot. Both cases without control perform considerably better than the case without control 
As mentioned, for the submerged buoy, $b(k)$ peaks at a larger $k$, at which the incident power spectral density value may be very small in swell-dominated spectra. Thus, in swelldominated spectra, tuning the damping to match $b\left(k_{\mathrm{p}}\right)$ and using this value for the entire spectrum is disadvantageous for the submerged buoy as it means rejecting a large amount of power over the $k>k_{\mathrm{p}}$ range that could have been absorbed with larger damping values. Near-optimum velocity control is thus likely to produce appreciably better results than peak-frequency control for the submerged buoy. This point is discussed further in Sect. 5.

In contrast, note that $b\left(k_{1}\right)$ for the floating buoy is greater and has a greater rate of increase at $k_{1}$, so that $b\left(k_{\mathrm{p}}\right)$ is considerably greater than for the submerged buoy. Therefore, for the floating buoy, matching the load damping to $b\left(k_{\mathrm{p}}\right)$ for the entire spectrum is comparatively less disadvantageous.

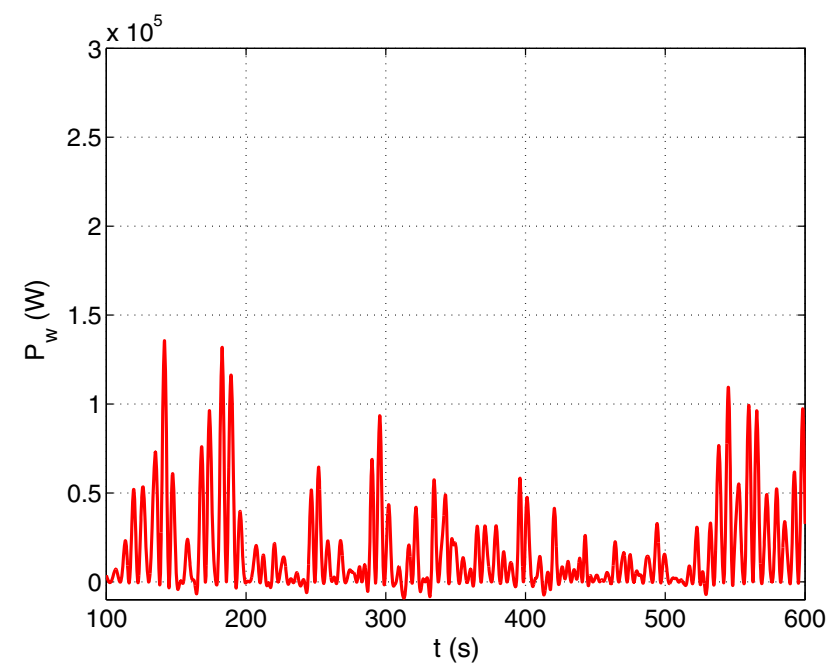

(a) Floating Buoy: Near-Optimum Control; $R=2 \mathrm{~m}$
Hence, peak-frequency tuning for the floating buoy may produce power absorption results that are not very much lower than with near-optimal control.

\section{Calculations}

Calculations were carried out for two floating and submerged cylindrical buoys. The radii were $R=2 \mathrm{~m}$ for the smaller buoy and $R=10 \mathrm{~m}$ for the larger. Note that diffraction effects may be considered negligible for the smaller size in swelldominated spectra. In each case, the draft was set at $D=R / 2$ for the floating buoys, while for the fully submerged configuration, the depth of immersion of the top surface was set at $D=R / 2$, which was also taken to be the height of the cylin-

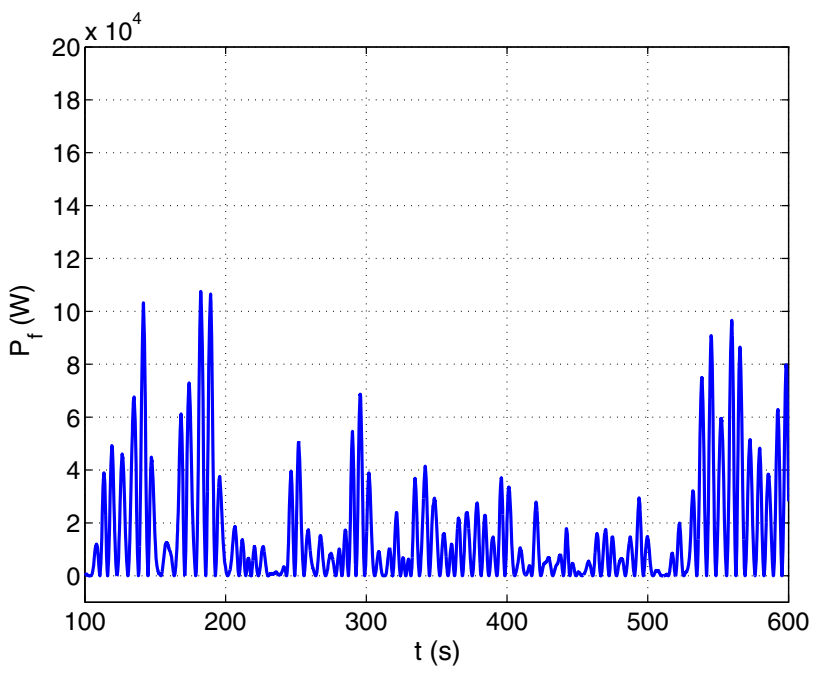

(b) Floating Buoy: Peak-Frequency Tuning; $R=2 \mathrm{~m}$

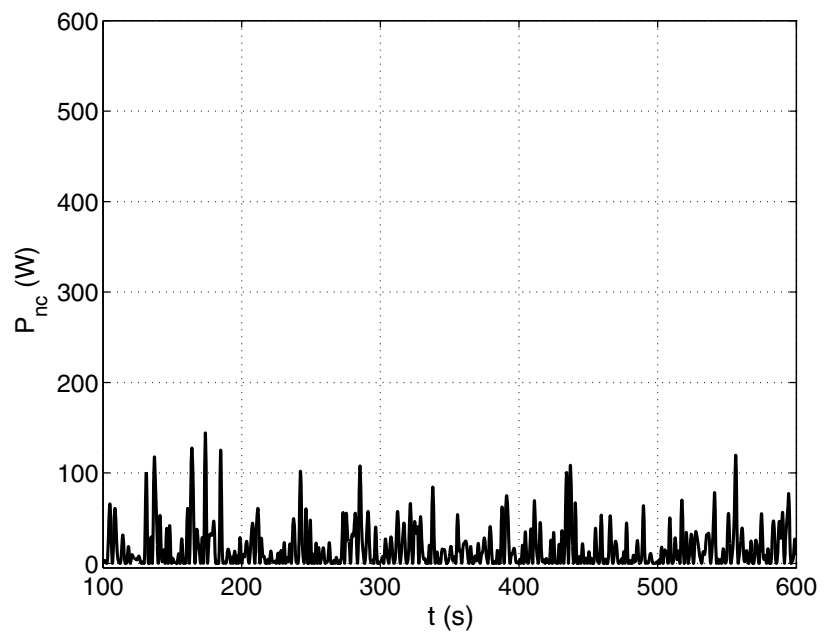

(c) Floating Buoy: Constant Damping; $R=2 \mathrm{~m}$

Fig. 9 The instantaneous power absorption by the $R=2 \mathrm{~m}$ buoy in a spectrum with $H_{\mathrm{s}}=1 \mathrm{~m}, T_{\mathrm{e}}=13 \mathrm{~s}$. Note that the vertical scale is different in the plot with constant damping. Further, the cases with control perform considerably better than the constant damping case 
der in the submerged configuration (see Fig. 1). A schematic for this device is shown in Fig. 1. The goal was to consider a size where diffraction was small, and a larger size with greater diffraction. The hydrodynamics software HYDRAN (HYDRAN 2012; Ertekin et al. 1993) was used to obtain the added mass, radiation damping, and exciting force variations for heave oscillation in both the floating and submerged configurations (see also Korde and Ertekin 2014; Nolte and Ertekin 2014). Time-domain calculations were carried out to evaluate the power absorption performance under the two control strategies discussed here, (1) near-optimal real-time control, and (2) non-real time peak-frequency control. These were compared both with each other and with a case where damping was held constant at $8 \mathrm{kNs} / \mathrm{m}$ in all spectra and no control was applied.

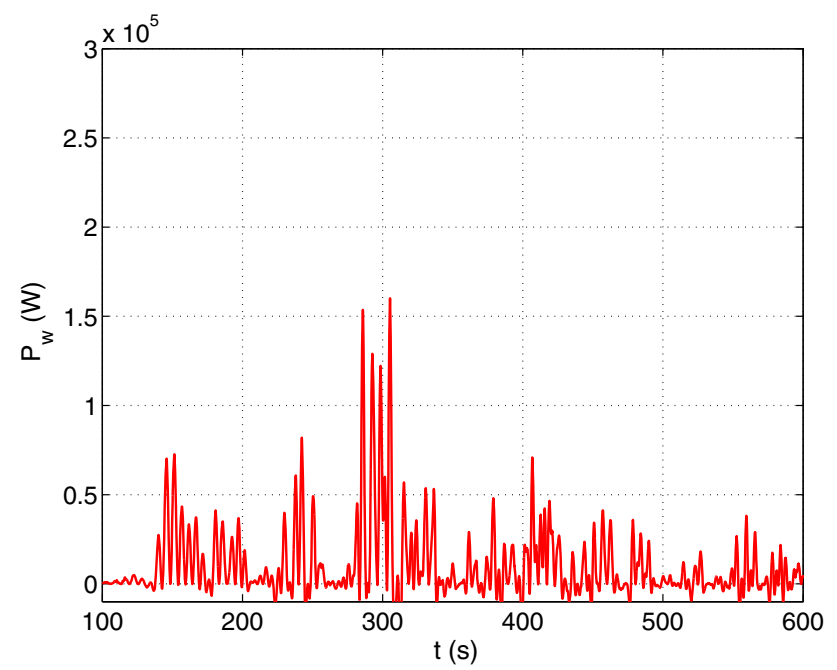

(a) Submerged Buoy: Near-Optimum Control; $R=2 \mathrm{~m}$
Results were obtained for several uni-modal (i.e., with a single, dominant peak frequency) 2-parameter PiersonMoskowitz-type spectra generated using the two parameters $H_{\mathrm{S}}$ and $T_{\mathrm{e}}$. For the results discussed here, $H_{\mathrm{s}}=1 \mathrm{~m}$, and $T_{\mathrm{e}}$ values $9 \mathrm{~s}, 13 \mathrm{~s}$, and $18 \mathrm{~s}$ were used. The corresponding irregular wave signals were obtained using the approach of Korde (2014) based on inverse Fourier transformation of the complex amplitude frequency variation and random phase between $[0,2 \pi]$. No displacement/velocity constraints were used in the time-domain calculations. Of particular interest to the calculations were (1) desired heave velocities under near-optimal control, (2) actual velocity using the present approach to near-optimal control, and (3) velocity under peak-frequency control, and (4) absorbed power variations under near-optimal control as applied, peak-frequency con-

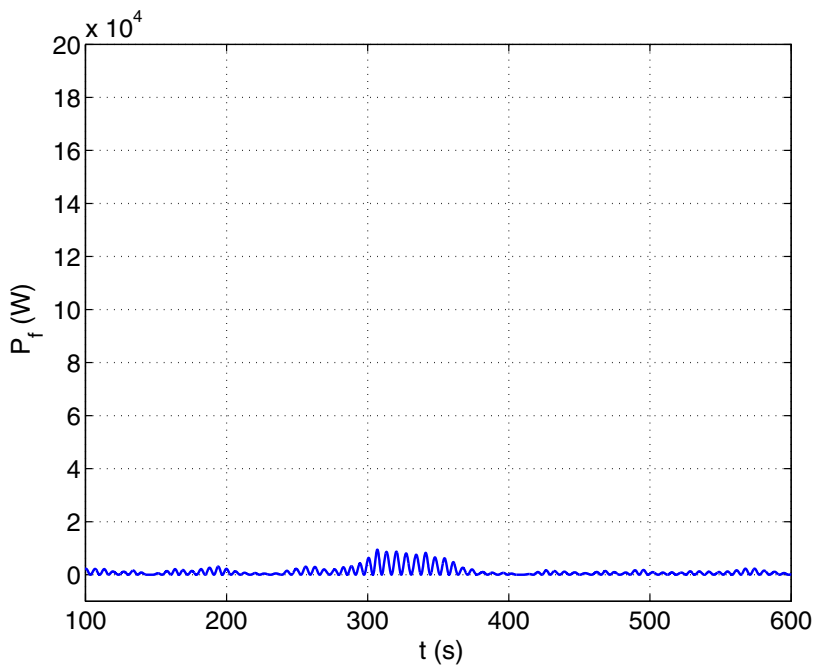

(b) Submerged Buoy: Peak-Frequency Tuning; $R=2 \mathrm{~m}$

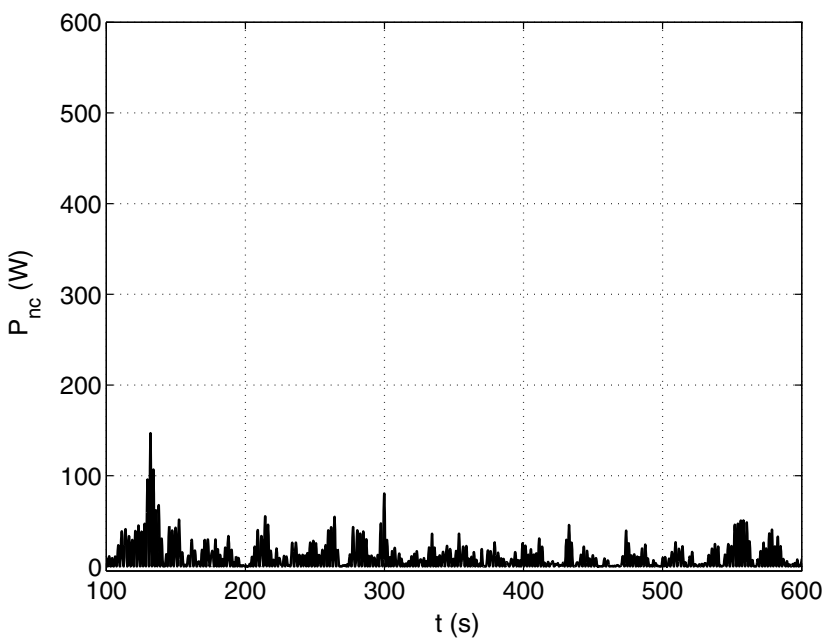

(c) Submerged Buoy: Constant Damping; $R=2 \mathrm{~m}$

Fig. 10 The instantaneous power absorption by the $R=2 \mathrm{~m}$ buoy in a spectrum with $H_{\mathrm{s}}=1 \mathrm{~m}, T_{\mathrm{e}}=13 \mathrm{~s}$. Note the vertical axis scale difference on the third plot. Further, the cases with control perform considerably better than the constant damping case 
trol, and constant damping. Calculation windows are set at $10 \mathrm{~min}$ in each case.

Frequency-domain calculations for absorbed power were also carried out to verify the findings from the time-domain calculations. All results here were obtained for both the floating and the submerged configurations. The following section discusses all of these results.

\section{Discussion of results}

As discussed in the previous sections, the configurations studied here have different wave-radiation properties. The floating cylinder heaving buoy radiates with its bottom surface only and resembles a point-source like monopole in long waves (for $k R<0.2$ ). On the other hand, although the heaving submerged cylinder buoy also radiates as a monopole, the top and the bottom faces counteract each other $(k R<0.2)$. This provides one explanation for their different behaviors under the two control approaches of this work. It is recalled that the present study only considers uni-modal spectra. In spectra with multiple peaks, control seeking reactive cancelation and optimum damping in real time can be expected to perform better than peak-frequency control tuned to one of the peaks. However, the goal here is to investigate conditions under which peak-frequency tuning may be a good practical choice.

As pointed out above and discussed in Sect. 3, waveradiation properties (specifically the radiation damping and its rate of variation in the low-frequency range) are impor-

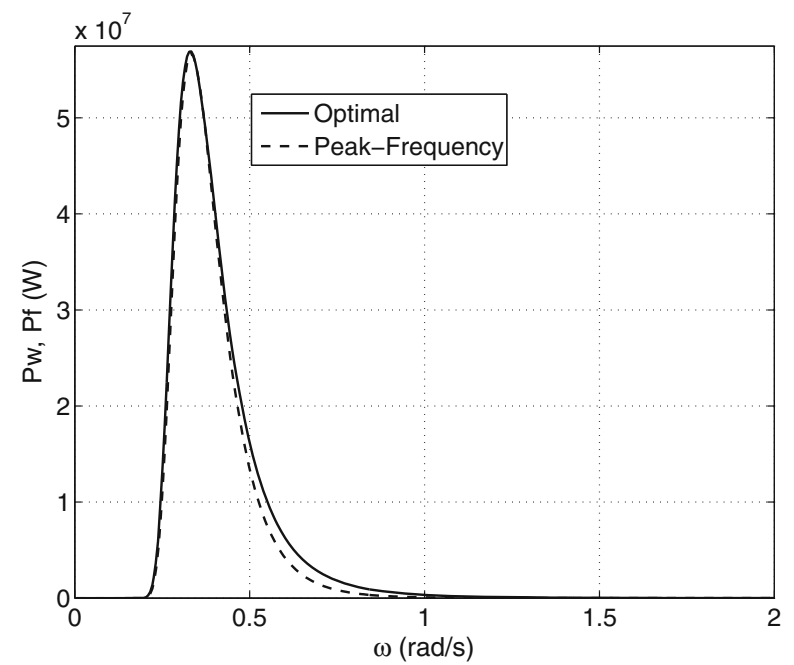

(a) Floating Buoy; $R=10 \mathrm{~m} ; T_{e}=18 \mathrm{~s}$

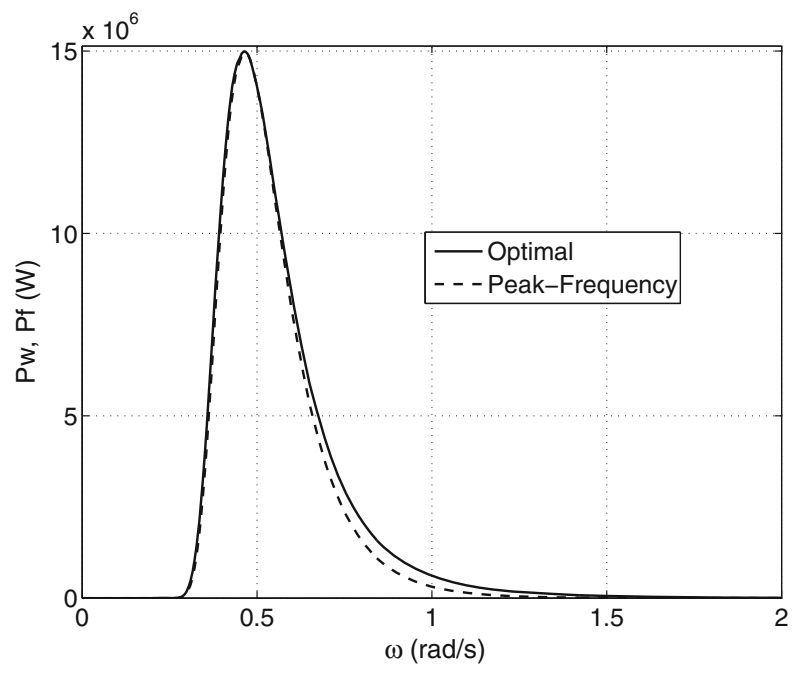

(b) Floating Buoy; $R=10 \mathrm{~m} ; T_{e}=13 \mathrm{~s}$

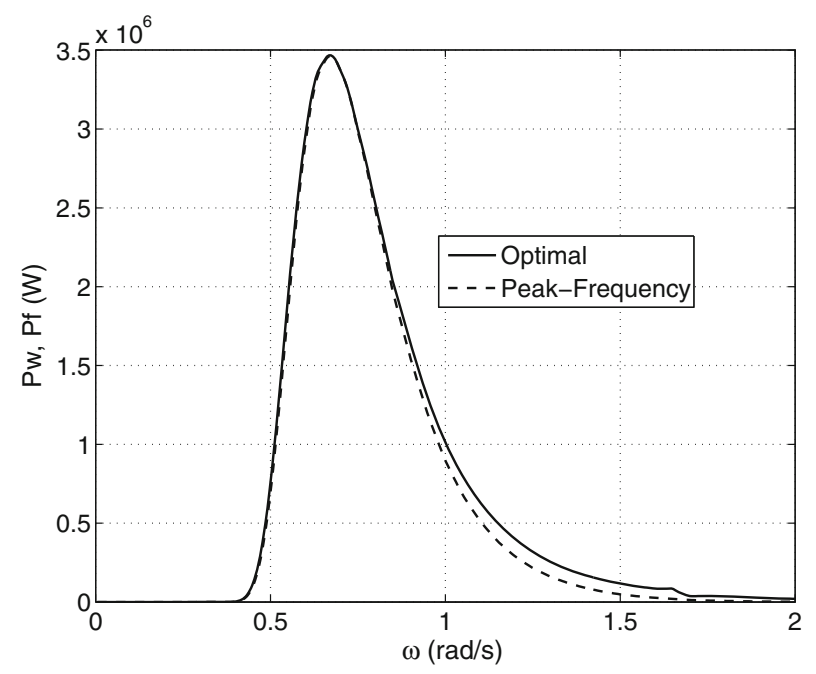

(c) Floating Buoy; $R=10 \mathrm{~m} ; T_{e}=9 \mathrm{~s}$

Fig. 11 Power Absorption with the two control strategies over a frequency-range without displacement constraints (floating buoy, $R=10 \mathrm{~m}$ ). For all three values of $T_{\mathrm{e}}$ the power absorption is comparable under optimal control and peak-frequency control 
tant to the difference in the relative effectiveness of the two control strategies. As Fig. 3 shows, near the peak period, the radiation damping value for the floating buoy is $b\left(k_{\mathrm{p}}\right)=$ $3.12 \times 10^{5} \mathrm{Ns} / \mathrm{m}$. This is about $62 \%$ of the maximum radiation damping value for the floating buoy. For the submerged buoy its value is $b\left(k_{\mathrm{p}}\right)=8.65 \times 10^{4} \mathrm{Ns} / \mathrm{m}$, which is about $3 \%$ of the maximum radiation damping value. It appears that setting the load damping at the peak-frequency radiation damping value will be significantly more representative of 'optimal' behavior for the floating buoy than the submerged buoy for this radius and spectral peak frequency. This difference will be enhanced for spectra with peaks at still lower $k R$ values, and reduced for spectra with peaks at greater $k R$ values. On the whole, it seems reasonable to expect that for heave-mode conversion, the performance gains from unconstrained near-optimal control over unconstrained peakfrequency control will be greater for the submerged buoys than for the floating buoys. This point is considered further in the following.

It is worth recalling that the time-domain application of Sect. 2 works best in long-wave dominated spectra due to the use of a single (maximum) group velocity $v_{\mathrm{mx}}$ for all frequencies. It is assumed here that this approximation affects both the floating and submerged buoys equally, and in future work it would be of interest to investigate whether the two configurations respond differently to the present single group velocity/long-wave assumption. Figure 5 shows the velocity results for the $R=10 \mathrm{~m}$ buoy when floating and submerged. Figures 7 and 8 show the power results for the 10-m buoy when floating and submerged in a spectrum with $H_{\mathrm{s}}=1.0 \mathrm{~m}$

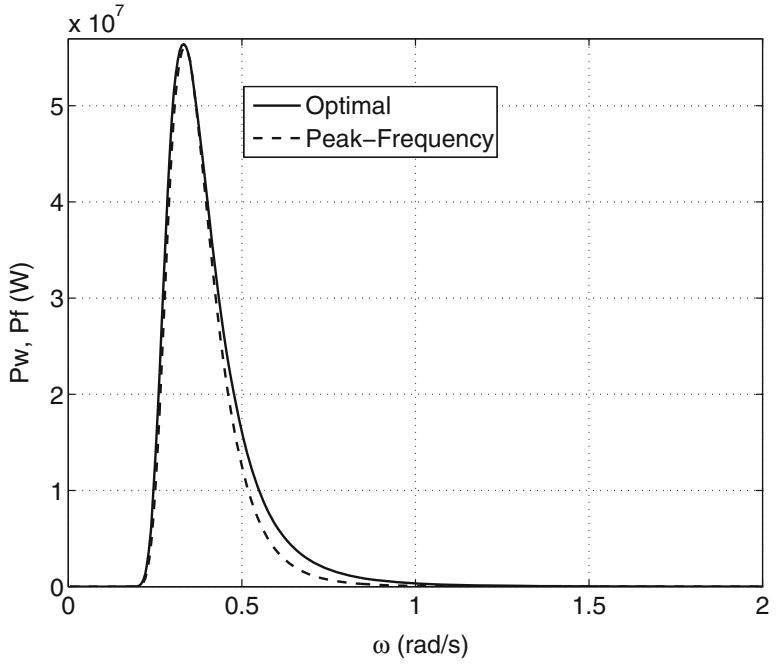

(a) Floating Buoy; $R=2 \mathrm{~m} ; T_{e}=18 \mathrm{~s}$

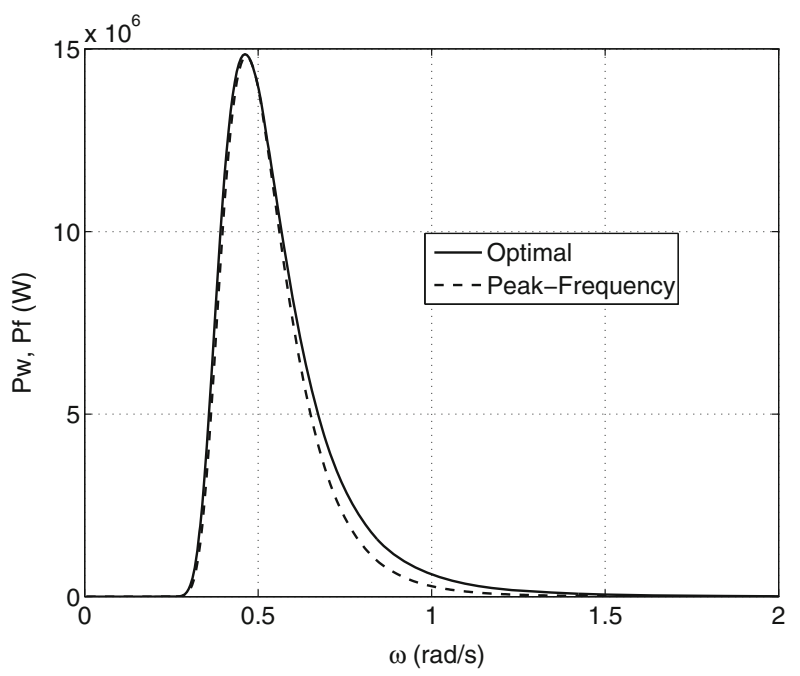

(b) Floating Buoy; $R=2 \mathrm{~m} ; T_{e}=13 \mathrm{~s}$

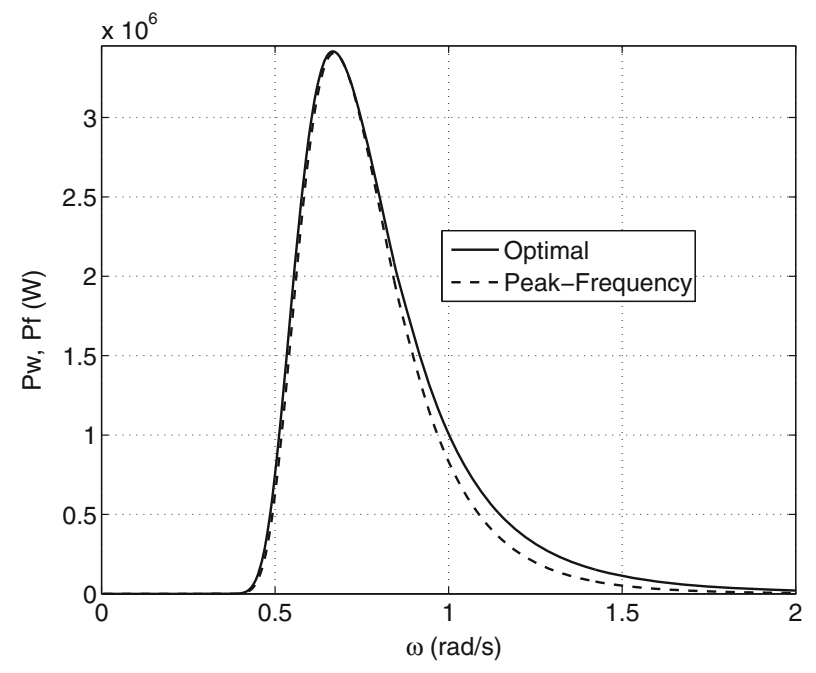

(c) Floating Buoy; $R=2 \mathrm{~m} ; T_{e}=9 \mathrm{~s}$

Fig. 12 Power Absorption with the two control strategies over a frequency-range without displacement constraints (floating buoy, $R=2 \mathrm{~m}$ ). For all three values of $T_{\mathrm{e}}$ the power absorption is comparable under optimal control and peak-frequency control 
and $T_{\mathrm{e}}=13 \mathrm{~s}$. In Fig. 5, for the floating case, the actual velocity with approximate near-optimum control is seen to be very close to the desired near-optimum velocity $v_{\mathrm{o}}$. The velocity with peak-frequency control $v_{\mathrm{m}}$ is also found to be close to $v_{\text {act }}$. On the other hand, for the submerged buoy, the difference between $v_{\mathrm{m}}$ and $v_{\mathrm{o}}$ is greater. This confirms the expectation above that peak-frequency control performs comparably to near-optimal control for the floating buoy, though falling short for the submerged buoy. The velocity results are similar for the $R=2 \mathrm{~m}$ buoy (Fig. 6), though for the $T_{\mathrm{e}}=13 \mathrm{~s}$ spectrum, the difference is now more pronounced for the submerged case given the smaller $k_{\mathrm{p}} D_{\mathrm{r}}$ value. Larger differences can be expected for the 10-m submerged

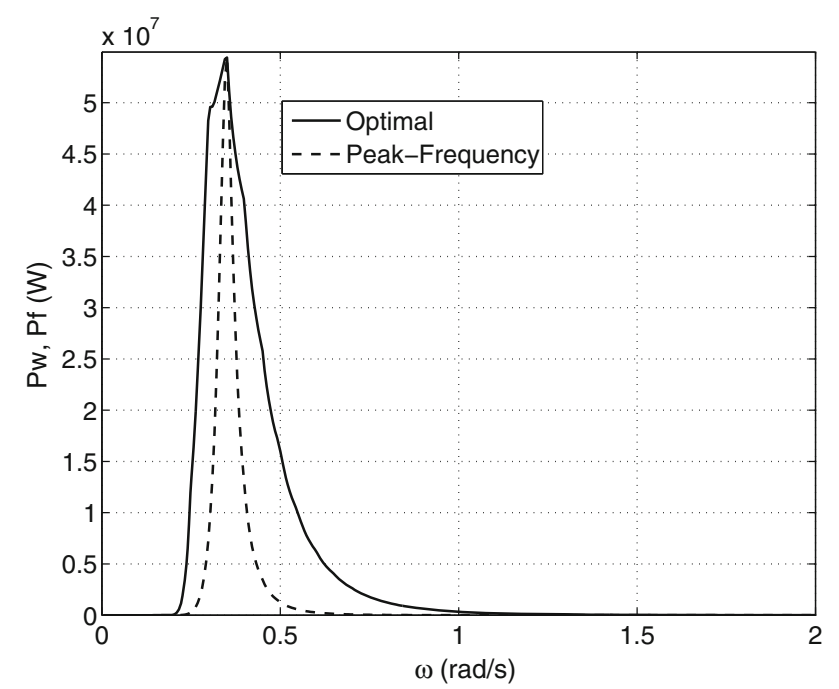

(a) Submerged Buoy; $R=10 \mathrm{~m} ; T_{e}=18 \mathrm{~s}$ buoy in spectra with $T_{\mathrm{e}}$ values for which the $k_{\mathrm{p}} D_{\mathrm{r}}$ value is smaller (see Sect. 3).

Figure 7 shows the absorbed power variation for the $10-\mathrm{m}$ floating buoy for the same spectrum $\left(T_{\mathrm{e}}=13 \mathrm{~s}\right)$. The difference in absorbed power with the two control strategies is seen to be small for this case as measured by the average capture efficiencies (5 and $4.8 \%$, respectively, for nearoptimal and peak-frequency tuning control). For comparison, the lowermost plot shows the absorbed power variation for a constant non-optimized pure damping load (note that the vertical scales are different for this plot). The average absorbed power and capture efficiency are found to be much lower for this case.

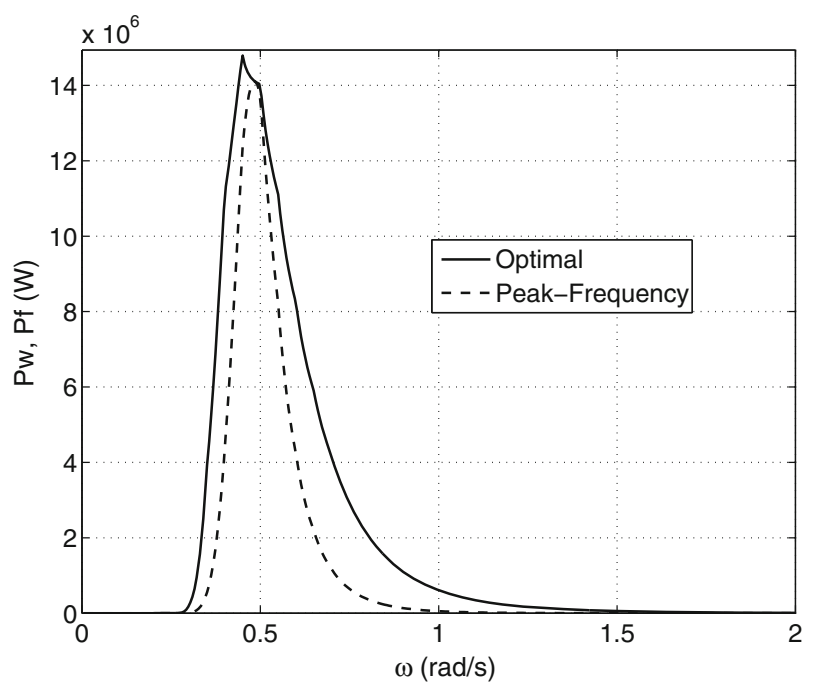

(b) Submerged Buoy; $R=10 \mathrm{~m} ; T_{e}=13 \mathrm{~s}$

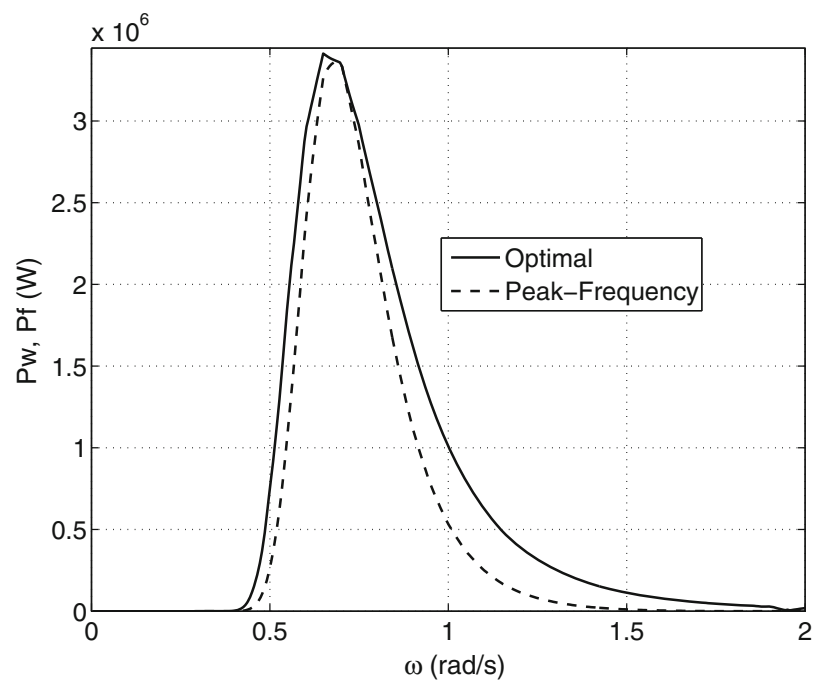

(c) Submerged Buoy; $R=10 \mathrm{~m} ; T_{e}=9 \mathrm{~s}$

Fig. 13 Power Absorption with the two control strategies over a frequency-range without displacement constraints (submerged buoy, $R=10 \mathrm{~m}$ ). For this submerged buoy with $R=10 \mathrm{~m}$, a greater difference is observed between the two cases with control in the spectra with longer energy periods 
Equivalent results for the submerged buoys are shown in Fig. 8. Near-optimal control performs better than peakfrequency tuning, and the difference between the two is expected to widen with increasing $T_{\mathrm{e}}$. Similar behavior is observed for the $R=2 \mathrm{~m}$ buoy (Figs. 9, 10), although the smaller $k_{\mathrm{p}} D_{\mathrm{r}}$ values lead to greater improvements with nearoptimal control. Practical implementation of the first two force terms in Eqs. (8) and (21) may require processing of noisy accelerometer signals, so that extensive filtering and direct displacement sensing may be necessary in practice.

Figures 11, 12, 13 and 14 provide some insight into the findings from the time-domain calculations above. Calculations were carried out in different spectra for absorbed power under the two control strategies. Displacement and

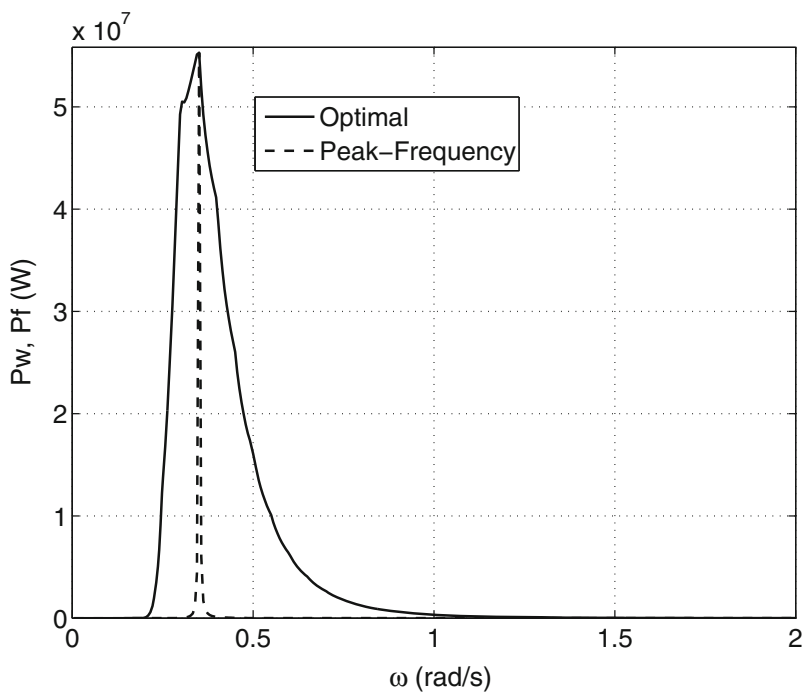

(a) Submerged Buoy; $R=2 \mathrm{~m} ; T_{e}=18 \mathrm{~s}$ velocity were left unconstrained here. The first few figures show the absorbed power without constraints at different frequencies for floating buoys. For the three spectra considered $\left(H_{\mathrm{s}}=1 \mathrm{~m} ; T_{\mathrm{e}}=9 \mathrm{~s}, T_{\mathrm{e}}=13 \mathrm{~s}\right.$, and $\left.T_{\mathrm{e}}=18 \mathrm{~s}\right)$ near-optimal control performs only somewhat better than peak-frequency tuning, the difference being greatest over the high $k R$ range where diffraction effects become more significant. This behavior is observed for both $2-\mathrm{m}$ and $10-\mathrm{m}$ radii in all three spectra. These results reflect the time-domain finding that $v_{\mathrm{m}}$ closely follows $v_{\text {act }}$ even if the control is only tuned to the spectral peak, and other points discussed above in relation to the floating cylinder buoys in heave. Further, consistent with the time-domain results, with the displacements unconstrained for the submerged buoys, the power

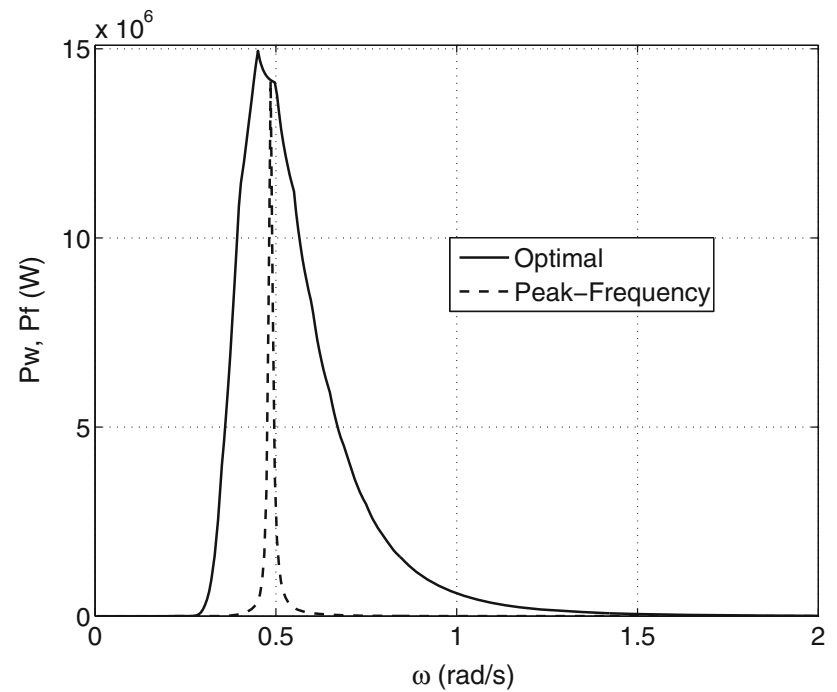

(b) Submerged Buoy; $R=2 \mathrm{~m} ; T_{e}=13 \mathrm{~s}$

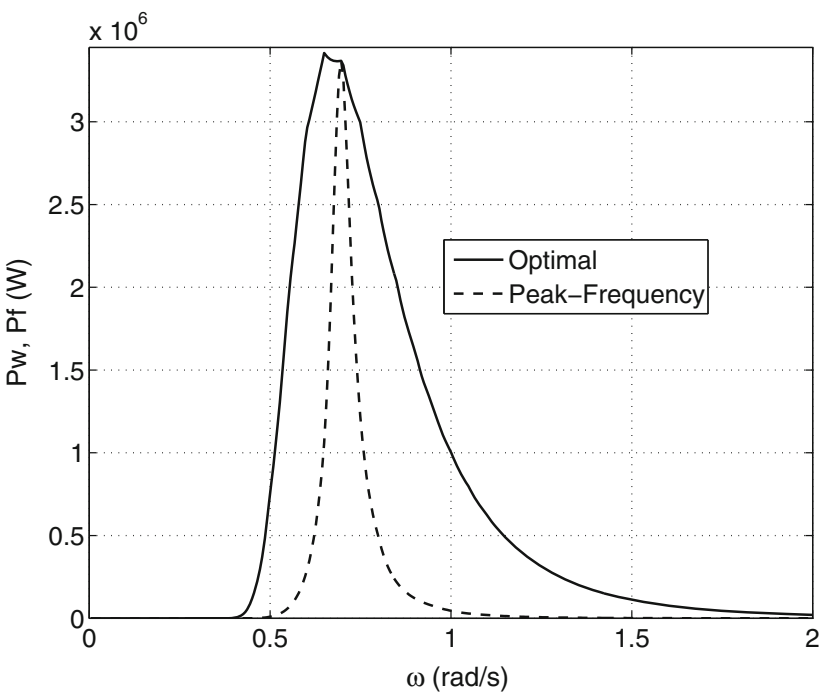

(c) Submerged Buoy; $R=2 \mathrm{~m} ; T_{e}=9 \mathrm{~s}$

Fig. 14 Power Absorption with the two control strategies over a frequency-range without displacement constraints (submerged buoy, $R=2 \mathrm{~m}$ ). Optimal control is seen to perform considerably better in all three spectra for the smaller submerged buoy with $R=2 \mathrm{~m}$ 
increase with near-optimal control over peak-frequency control is considerably greater here. It should be noted, however, that due to the very high velocities for both floating and submerged buoys, unconstrained behavior for the $R=2 \mathrm{~m}$ buoy (as well as the $R=10 \mathrm{~m}$ buoy in long energy periods) is mostly only of theoretical interest.

To summarize, it appears reasonable to propose that for small heaving absorbers with a dominant Froude-Krylov component in low-amplitude long waves, peak-frequency tuning may be adequate in long-wave dominated uni-modal spectra. Thus, for such heaving absorbers small enough to be considered monopole radiators, peak-frequency tuning may be a more practical choice if the expected wave climates are dominated by long swells at low amplitudes. Heaving radiators such as the submerged buoys with two radiating surfaces counteracting have less effective radiation and smaller Froude-Krylov forces at long periods, and appear to perform better in low-amplitude long waves under control seeking a phase match over the entire spectrum than under peak-frequency tuning. Waves in the range $k R \leq 0.2$ may be considered long waves here, and these points are more likely relevant to wave amplitudes small enough not to require displacement constraints. In the presence of displacement constraints preventing a full-amplitude response, control seeking a phase match over entire long-wave dominated spectra should probably be preferred for both floating and submerged heaving absorbers. However, the authors' work on this aspect is still ongoing and may be reported in a future paper.

\section{Conclusions}

The focus of this paper was on heaving, cylindrical (vertical) buoys being used for wave energy conversion relative to a stationary reference. Two reactive control strategies were examined for operation in long-crested irregular waves described by long-period single-peak spectra. A strategy leading to a time-domain implementation based on direct use of up-wave surface elevation measurements was compared with a non-real time tuning approach where the reactive forces were tuned for resonance and optimum damping at the spectral peak frequency. Calculations were carried out for two buoy sizes, one with negligible diffraction and other where diffraction effects were greater. Based on an approximate analysis, it was found that the dominant presence of the Froude-Krylov force component for the heaving floating buoys implied that in spectra where low-frequency/longperiod swells predominate, the approximate near-optimum time-domain strategy performs somewhat better than the peak-frequency tuning strategy. On the other hand, for the submerged buoys, because of the relatively small radiation over $k R<0.2$ and large relative contribution of the radiation/diffraction as $k R>0.2$, correct tuning at each frequency becomes important, and near-optimal control in the time domain enables considerably better power absorption than peak-frequency tuning. Approximate frequency-domain analysis was carried out to enable further insight into this finding.

Acknowledgments UAK thanks the support of Larry and Linda Pearson and the SDSM\&T Foundation through the Pearson endowment. The authors thank the anonymous reviewers for their comments and suggestions for improving this paper.

\section{References}

Babarit A, Clement AH (2006) Optimal latching control of a wave energy device in regular and irregular waves. Appl Ocean Res 28(2):77-91

Bacelli G, Ringwood JV (2012) A geometric tool for the analysis of position and force constraints in wave energy converters. Ocean Eng 65:10-18

Budal K, Falnes J (1980) Interacting point absorbers with controlled motion. In: Count BM (ed) Power from Sea Waves. Academic Press, London, pp 381-399

Ertekin RC, Riggs HR, Che X, Du S (1993) Efficient methods for hydroelastic analysis of very large floating structures. J Ship Res 37(1):58-76

Evans DV (1981) Power from water waves. Ann Rev Fluid Mech 13:157-187

Falcao AFO (2008) Phase control through load control of oscillating body wave energy converters with hydraulic PTO system. Ocean Eng 35:358-366

Falcao AFO, Justino P (1999) OWC wave energy devices with air flow control. Ocean Eng 26(12):1275-1295

Falnes J (1995) On non-causal impulse response functions related to propagating water waves. Appl Ocean Res 17(6):379-389

Falnes J (2002) Ocean Waves and Oscillating Systems: Linear interactions including wave-energy extraction, Chapter 5. Cambridge University Press, Cambridge

Falnes J, Hals J (2012) Heaving buoys, point absorbers and arrays. Philos Trans R Soc A 370:246-277

Fusco F, Ringwood JV (2012) A study of the prediction requirements in real-time control of wave energy converters. IEEE Trans Sustain Energy 3(1):176-184

Fusco F, Ringwood JV (2013) A simple and effective real-time controller for wave energy converters. IEEE Trans Sustain Energy $4(1): 21-30$

Fusco F, Ringwood JV (2014) A hierarchical robust control of oscillating wave energy converters with uncertain dynamics. IEEE Trans Sustain Energy 5(3):958-966

Hals J, Falnes J, Moan T (2011) A comparison of selected strategies for adaptive control of wave energy converters. J Offshore Mech Arct Eng 133(3):1-12

Hansen R, Kramer M (2011) Modeling and control of the wave star prototype. In: Proceedings of 9th European Wave and Tidal Energy Conference. Southampton, UK, p 163

Hoskin R, Count B, Nichols N, Nicol D (1985) Phase control for the oscillating water column. In: Evans DV, de O Falcão AF (eds) Proceedings of IUTAM Symposium Hydrodynamics of Wave Energy Utilization. Springer, Berlin, pp 257-268

HYDRAN (2012) A computer program for the hydroelastic response analysis of ocean structures. Tech. rep., Offcoast Inc., Kailua, HI, ver. 5.1 .7 
Jeffreys ER (1984) Simulation of wave power devices. Appl Ocean Res 6(1):31-39

Korde UA (1991) A power take-off mechanism for maximizing the performance of an oscillating water column wave energy device. Appl Ocean Res 13(2):75-81

Korde UA (1999) Efficient primary energy conversion in irregular waves. Ocean Eng 26:625-651

Korde UA (2001) Phase control of floating bodies from an on-board reference. Appl Ocean Res 23:251-262

Korde UA (2014) On a near-optimal control approach for a wave energy converter in irregular waves. Appl Ocean Res 46:79-93

Korde UA, Ertekin RC (2014) On wave energy conversion and focusing in open water. Renew Energy 62:84-99

Korde UA, Schoen MP, Lin F (2002) Strategies for time-domain control of wave energy devices in irregular waves. In: Proceedings of 11th International Society Offshore and Polar Engeenierung (ISOPE) Conference. Stavanger, Norway

McCormick ME (1981) Ocean Wave Energy Conversion. John Wiley and Sons, NY (reissued with revisions, 2007, Dover, NY)

Naito S, Nakamura S (1985) Wave energy absorption in irregular waves by feedforward control system. In: Evans D, de O Falcão A (eds) Proceedings of IUTAM Symposium Hydrodynamics of Wave Energy Utilization, Springer, Berlin, pp 269-280
Nebel P (1992) Maximizing the efficiency of wave-energy plants using complex conjugate control. Proc IMechE Part I J Syst Control Eng 206(4):225-236

Nolte J, Ertekin RC (2014) Wave power calculations for a wave energy conversion device connected to a drogue. J Renew Sustain Energy (AIP) 6(1):013,117-1-013,117-21. doi:10.1063/1.4862785

Perdigao J, Sarmento A (1989) A phase control strategy for OWC devices in irregular waves. In: Grue J (ed) Proceedings of 4th International Workshop on Water Waves and Floating Bodies, pp 205-209

Salter SH (1978) Development of the duck concept. In: Proceedings of Wave Energy Conference. Heathrow, UK

Wehausen JV (1971) Motion of floating bodies. Ann Rev Fluid Mech 3:237-268

Wehausen JV (1992) Causality and the radiation condition. J Eng Math 26:153-158

Yeung RW, Peiffer A, Tom N, Matlock T (2012) Design, analysis, and evaluation of the UC-berkeley wave energy extractor. J Offshore Mech Arct Eng 134, 021902, p. 8 